Supporting Information

\title{
Strategic Design Bifunctional NiFeCoW@NC Hybrid to Replace the Noble Platinum for Dye-Sensitized Solar Cells and Hydrogen Evolution Reactions
}

Ting Wang, Ming Xu, Chunhui Ma, Yitong Gu, Weichao Chen*, Yunjiang Li, Jian Gong*, Tuo Ji, Weilin Chen*

Key Laboratory of Polyoxometalate and Reticular Material Chemistry of Ministry of

Education, Department of Chemistry, Northeast Normal University, Changchun 130024, P. R. China

*E-mail: chenw1@nenu.edu.cn; chenwc061@nenu.edu.cn; gongj823@nenu.edu.cn Tel: +86-431-85098787; Fax: +86-431-85098787. 


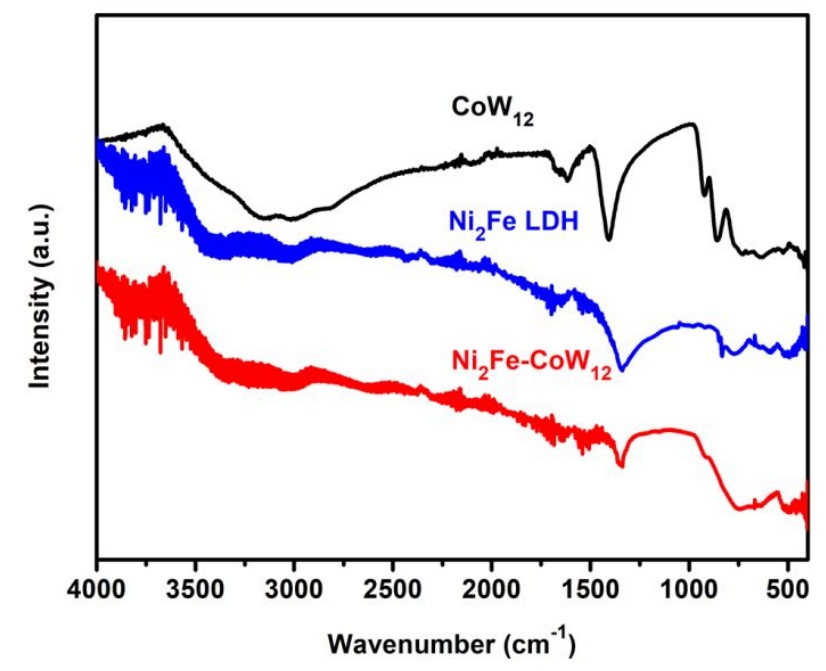

Figure S1. IR spectrum of $\mathrm{CoW}_{12}, \mathrm{Ni}_{2} \mathrm{Fe} \mathrm{LDH}$ and $\mathrm{Ni}_{2} \mathrm{Fe}-\mathrm{CoW} 12$ intercalated material.

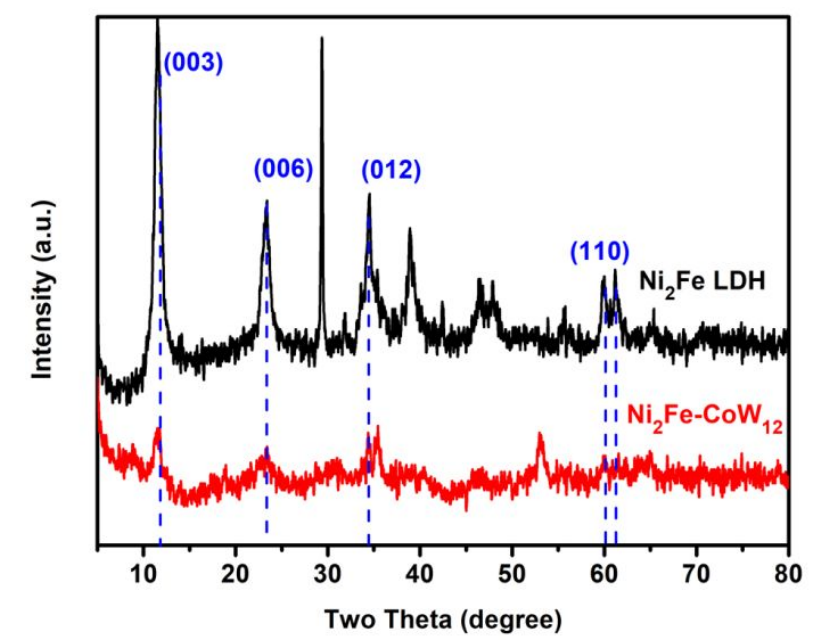

Figure S2. XRD of $\mathrm{Ni}_{2} \mathrm{Fe} \mathrm{LDH}$ and $\mathrm{Ni}_{2} \mathrm{Fe}-\mathrm{CoW}_{12}$ intercalated material.
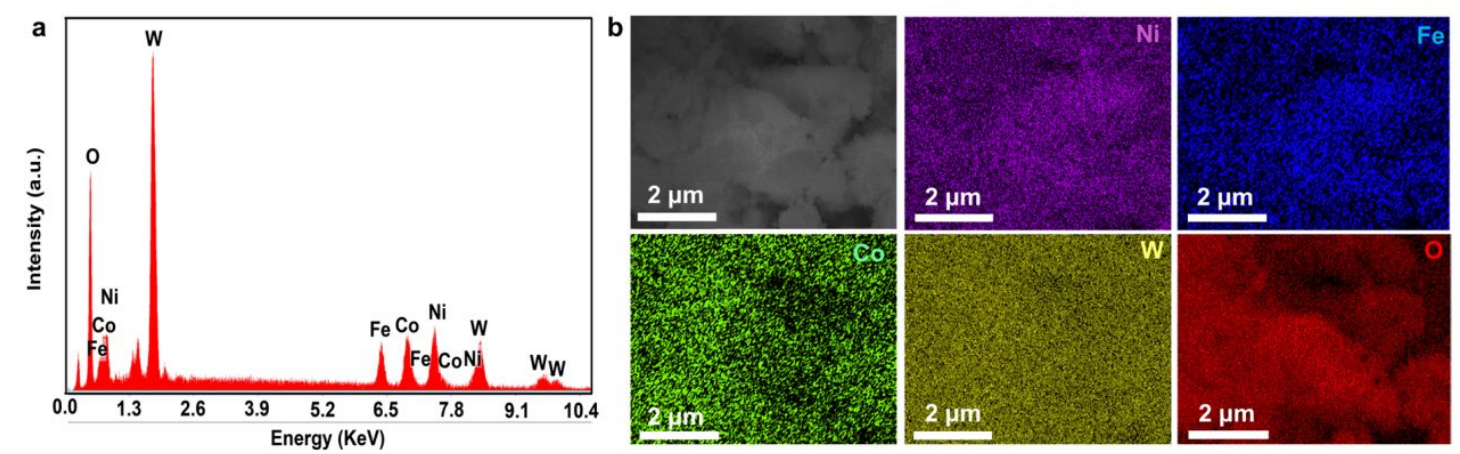

Figure S3. EDS and corresponding elemental mappings of $\mathrm{Ni}_{2} \mathrm{Fe}-\mathrm{CoW} \mathrm{W}_{12}$ intercalated material. 

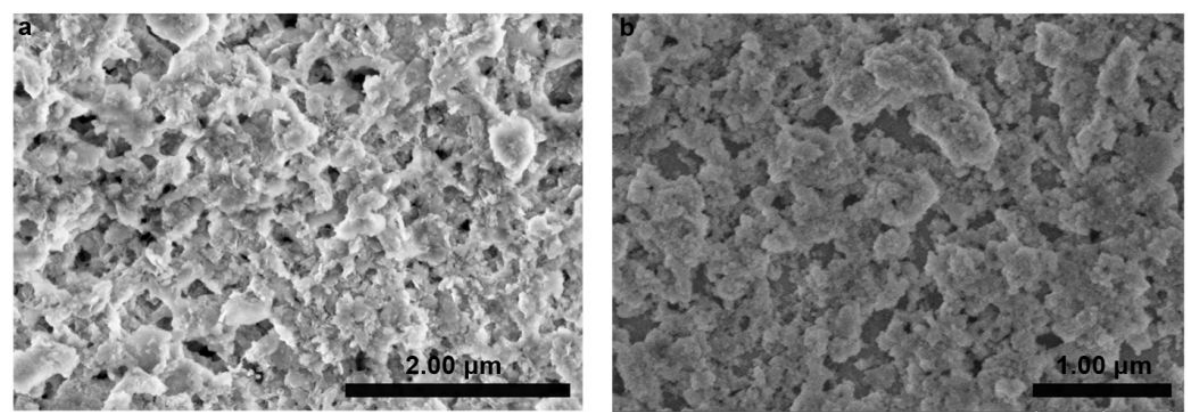

Figure S4. SEM images of $\mathrm{Ni}_{2} \mathrm{Fe} \mathrm{LDH}$ and $\mathrm{Ni}_{2} \mathrm{Fe}-\mathrm{CoW}{ }_{12}$ intercalated material.

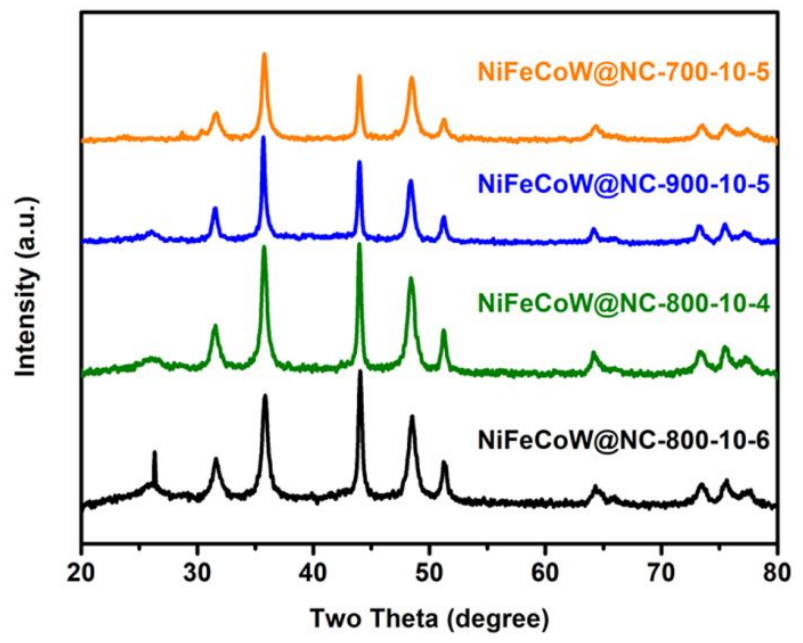

Figure S5. XRD patterns of NiFeCoW@NC-T-10-5 and NiFeCoW@NC-800-10-t.
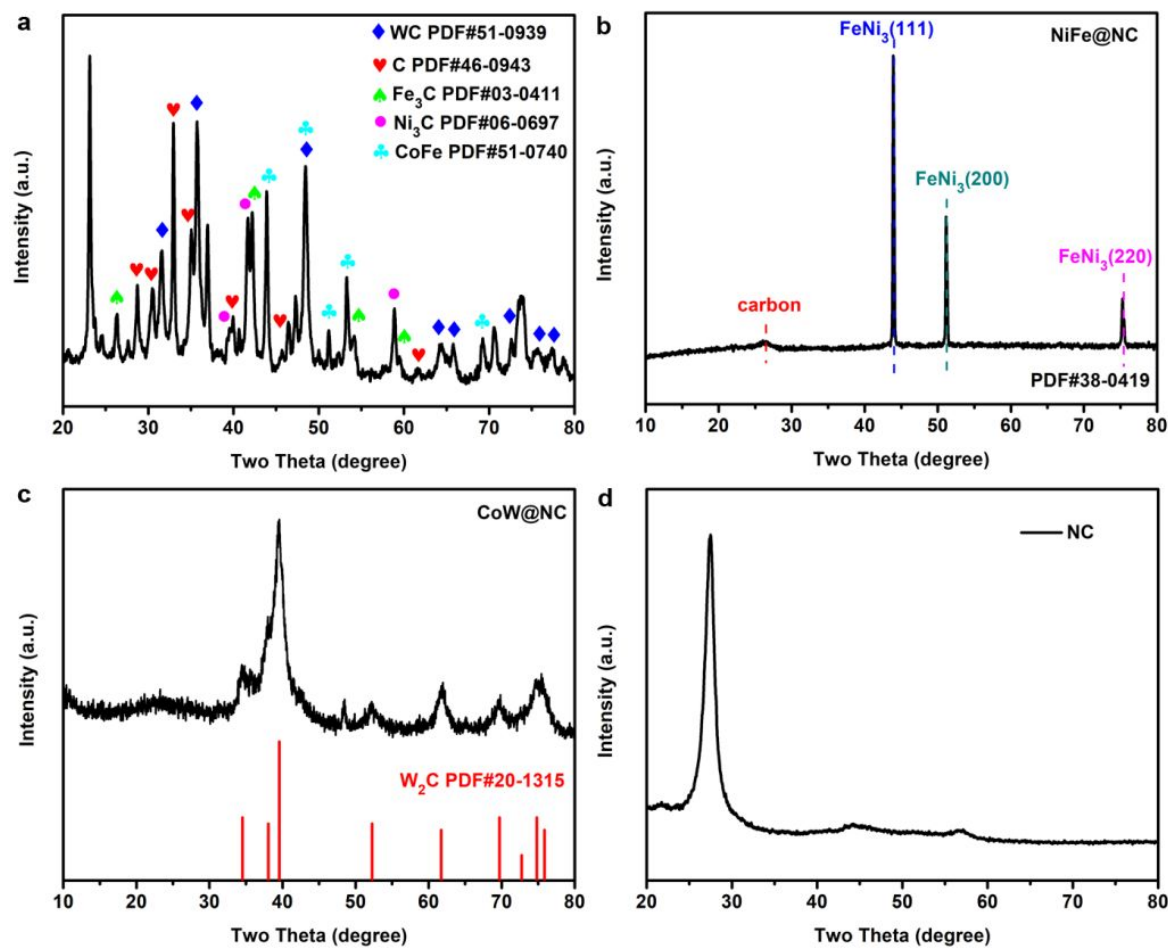

Figure S6. XRD patterns of p-NiFeCoW@NC, NiFe@NC, CoW@NC and NC. 

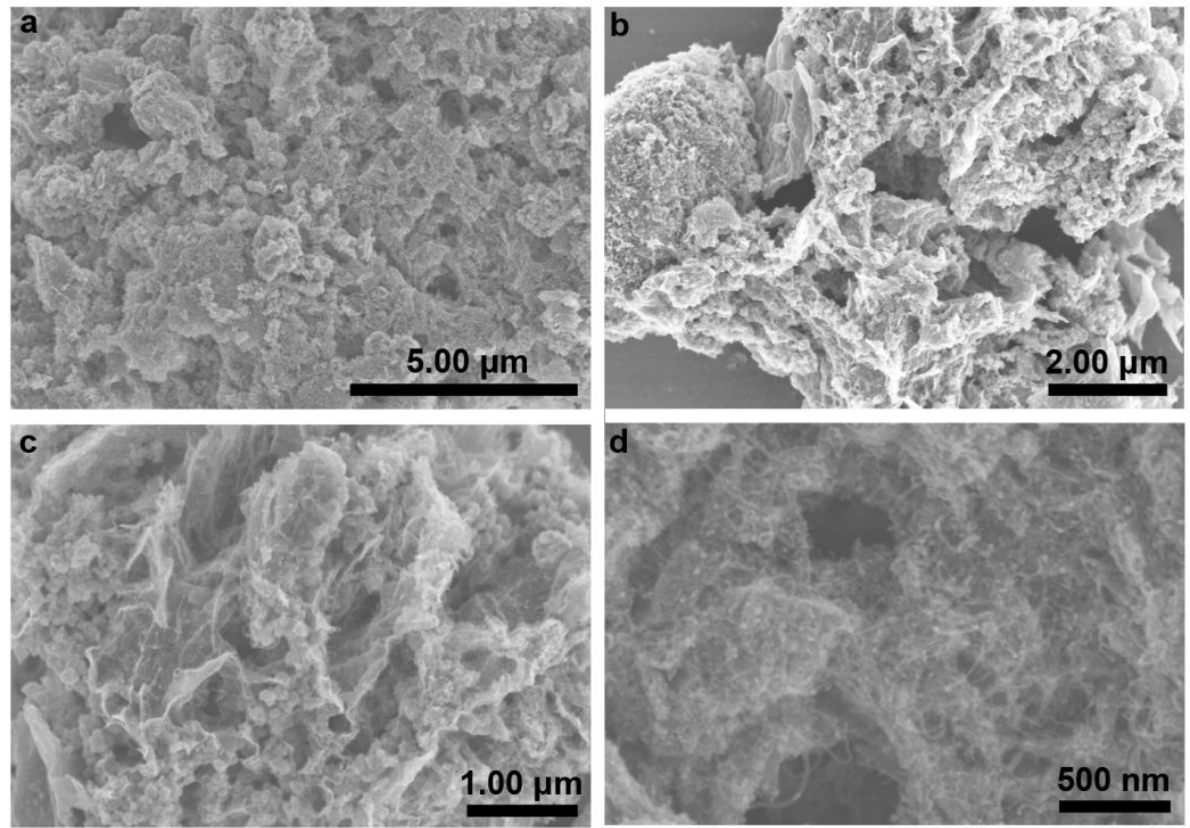

Figure S7. SEM images of NiFeCoW@NC-800-6-5.
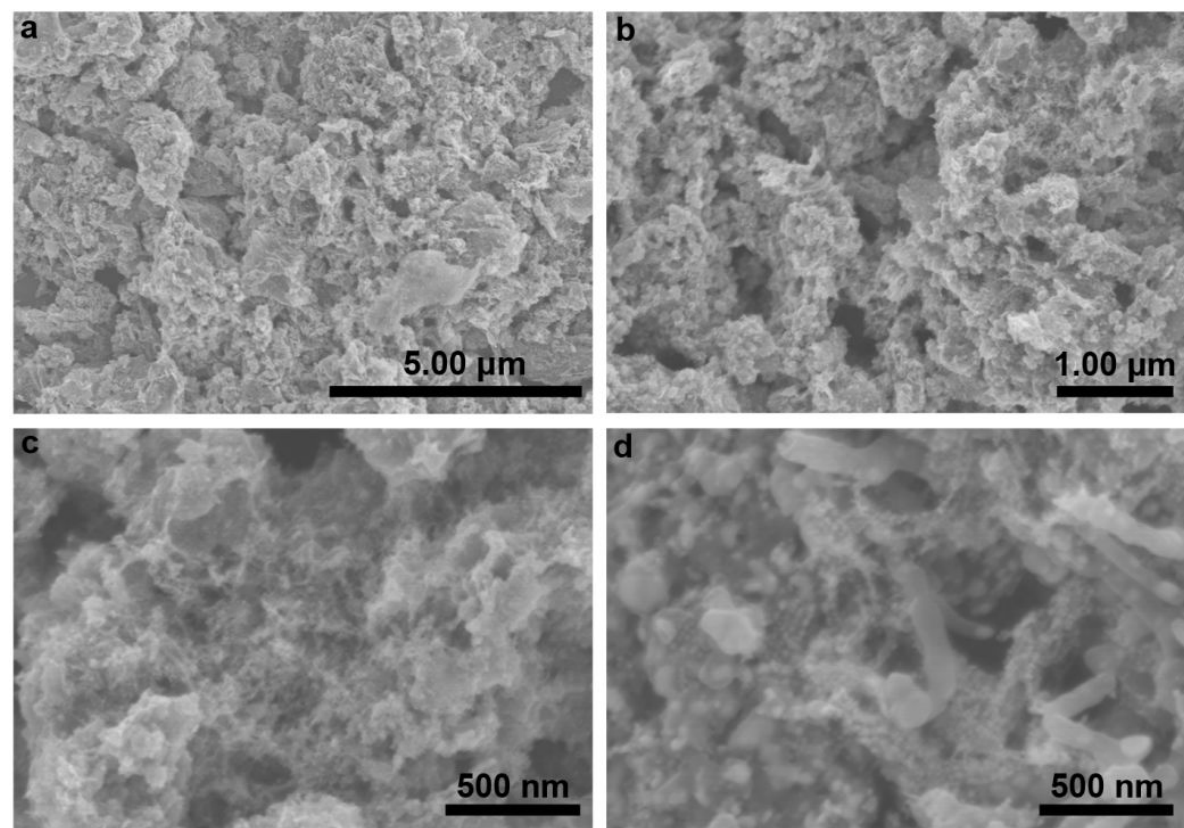

Figure S8. SEM images of NiFeCoW@NC-800-7-5. 

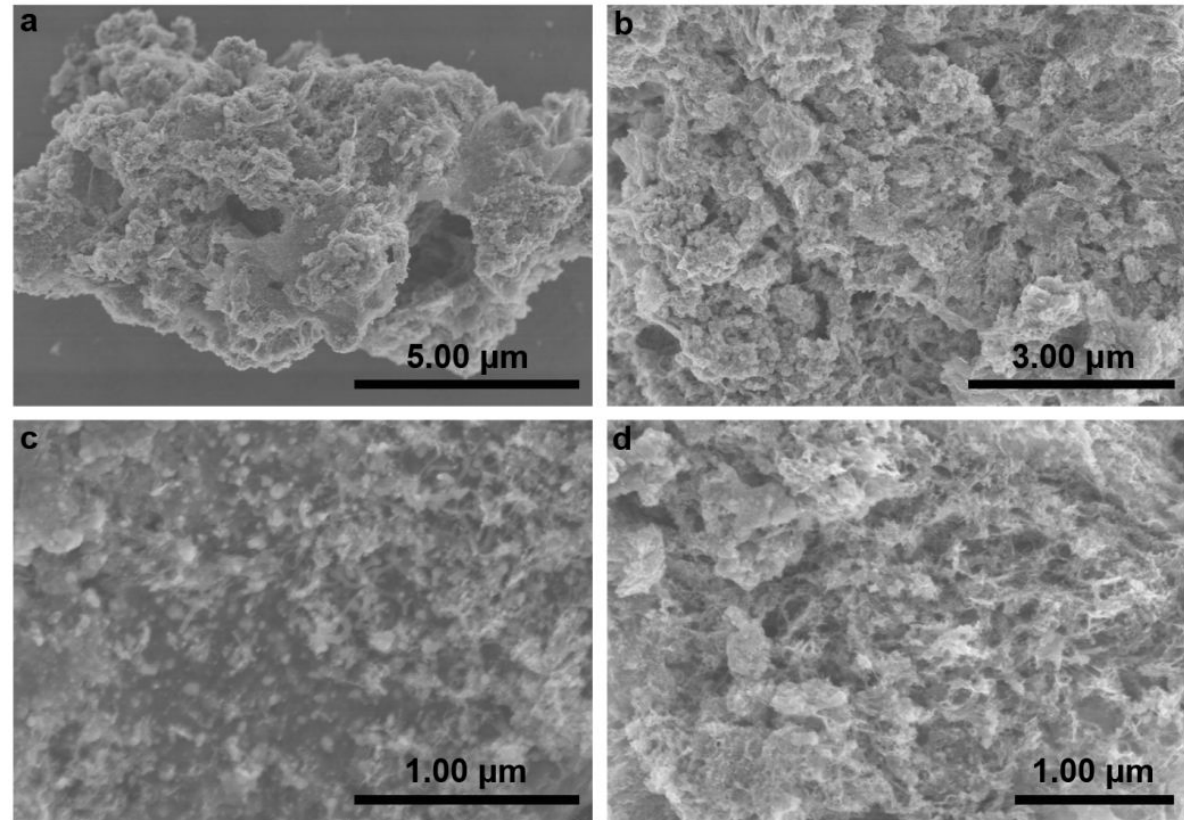

Figure S9. SEM images of NiFeCoW@NC-800-8-5.
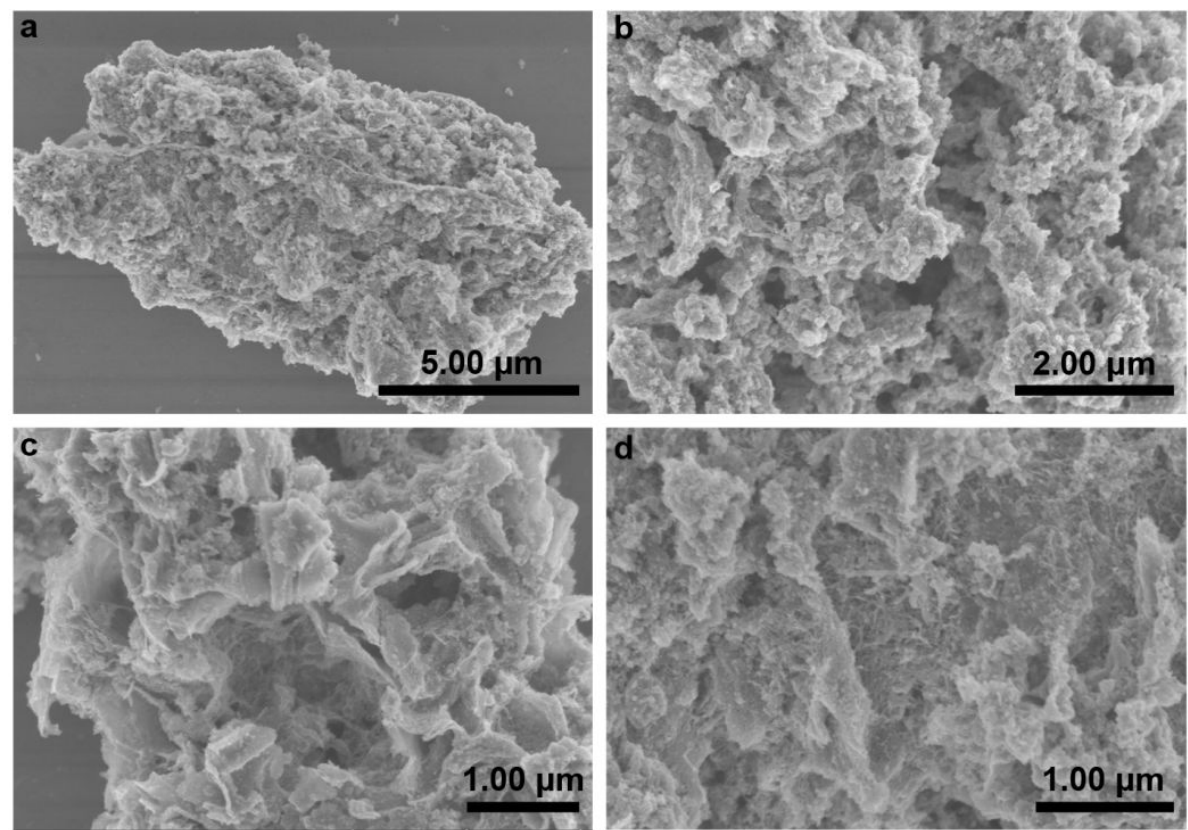

Figure S10. SEM images of NiFeCoW@NC-800-9-5. 

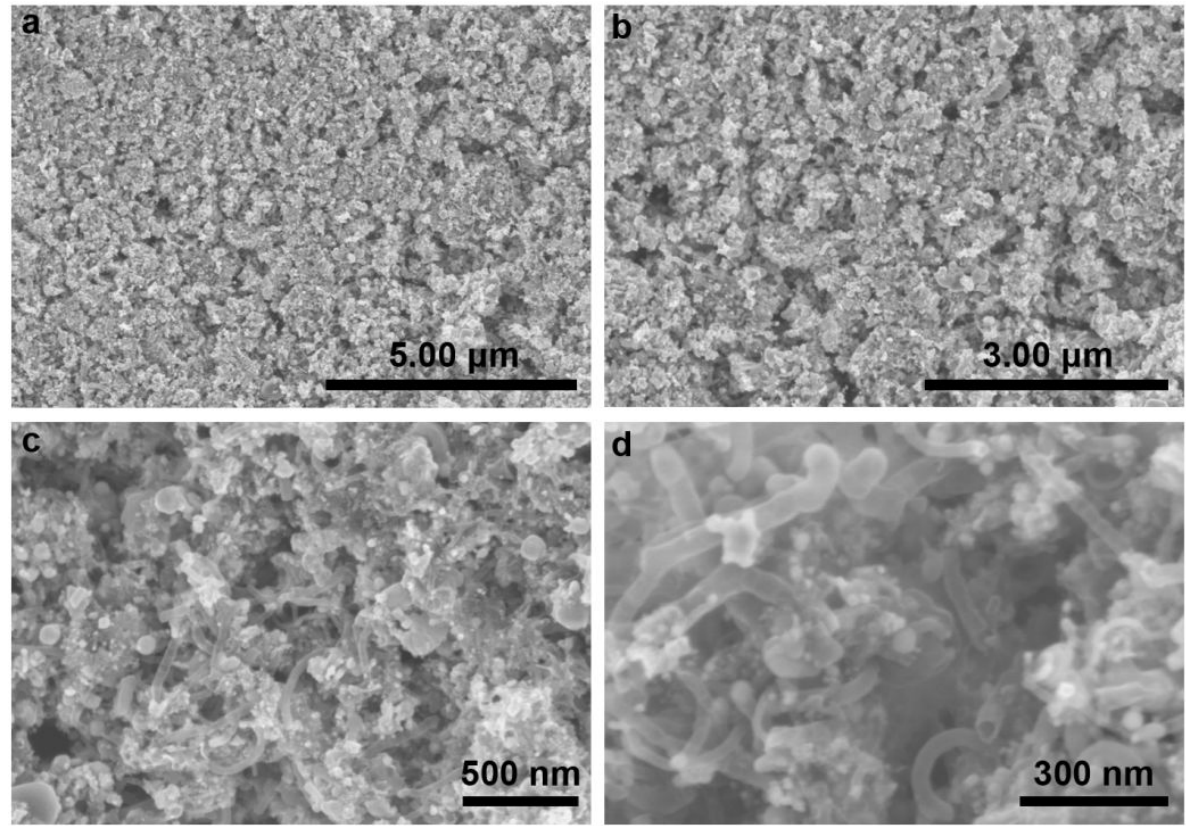

Figure S11. SEM images of NiFeCoW@NC-800-11-5.
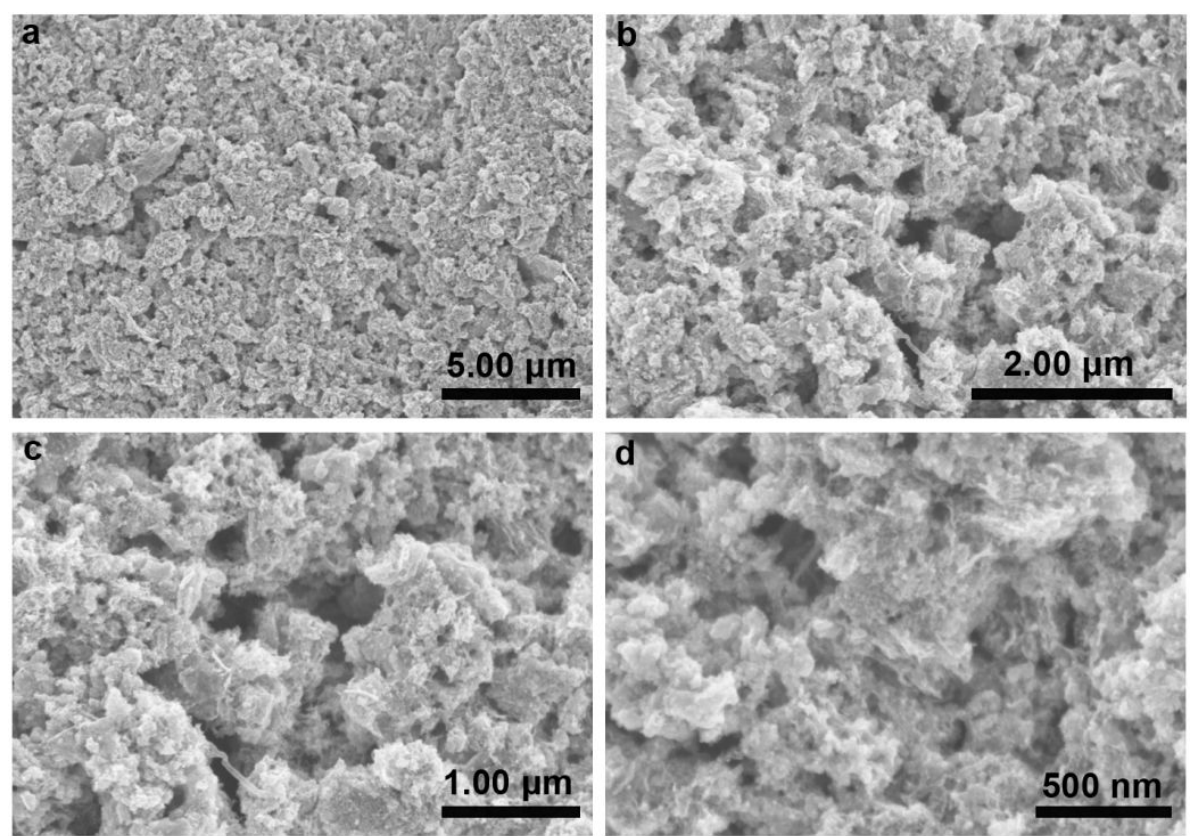

Figure S12. SEM images of NiFeCoW@NC-800-12-5. 

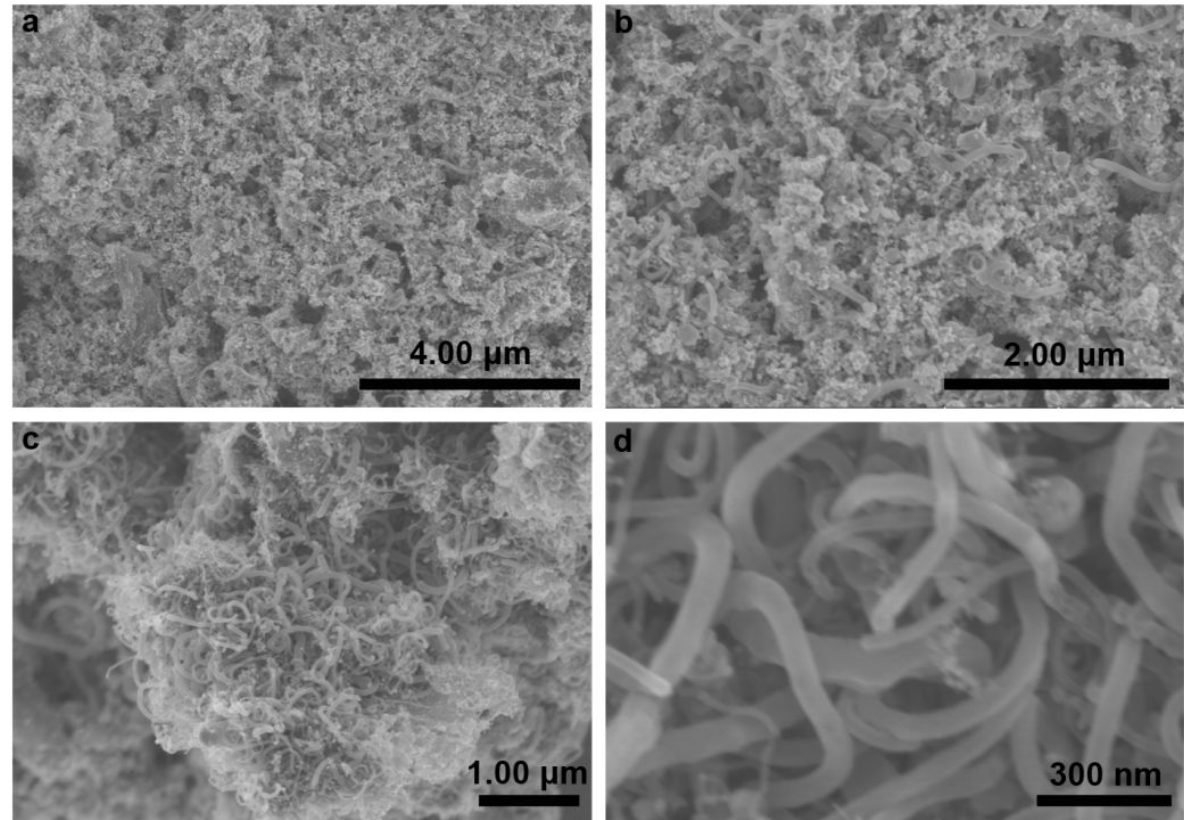

Figure S13. SEM images of NiFeCoW@NC-800-13-5.
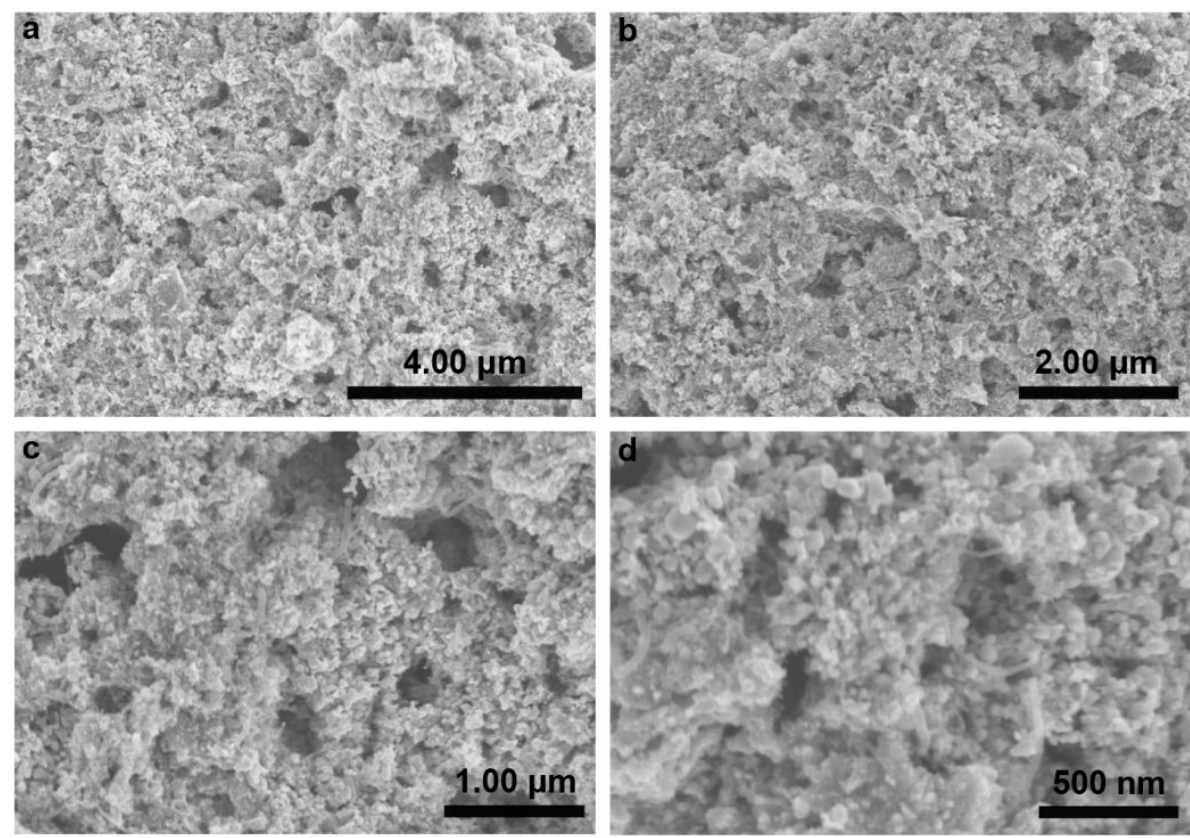

Figure S14. SEM images of NiFeCoW@NC-700-10-5. 

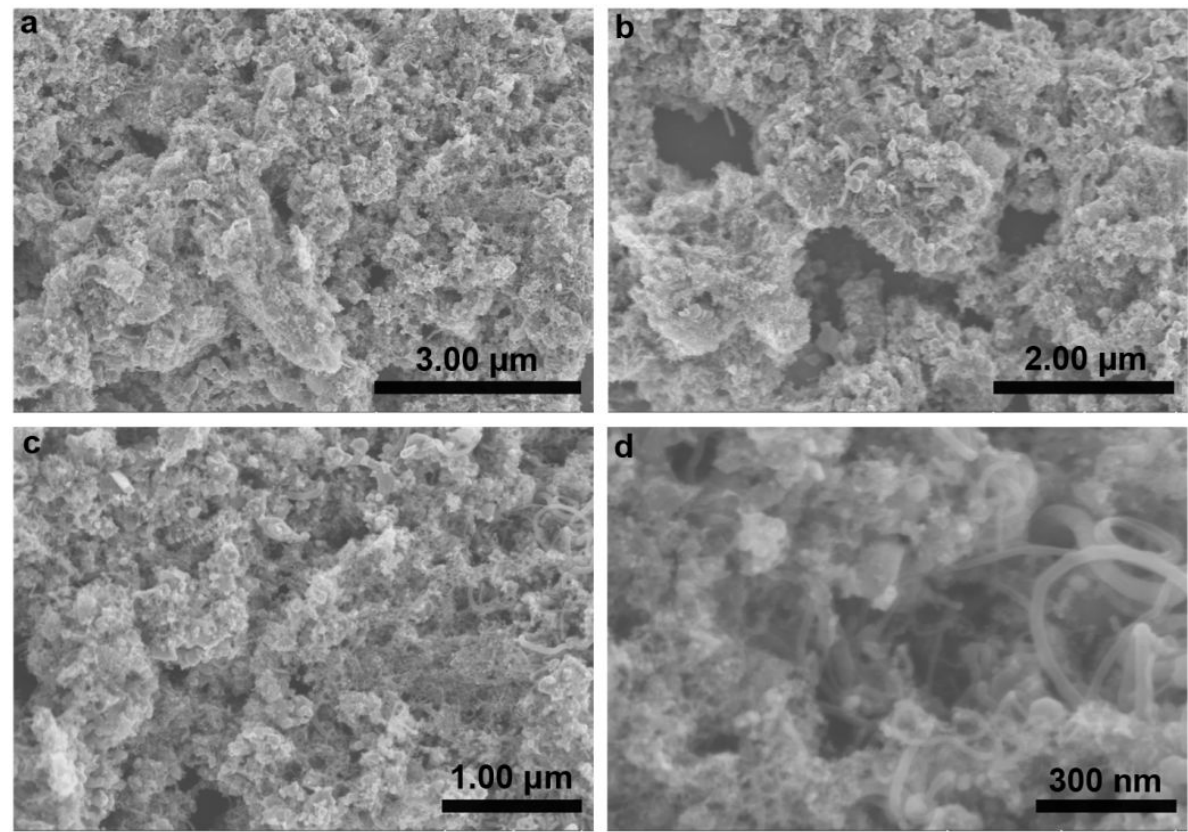

Figure S15. SEM images of NiFeCoW@NC-900-10-5.
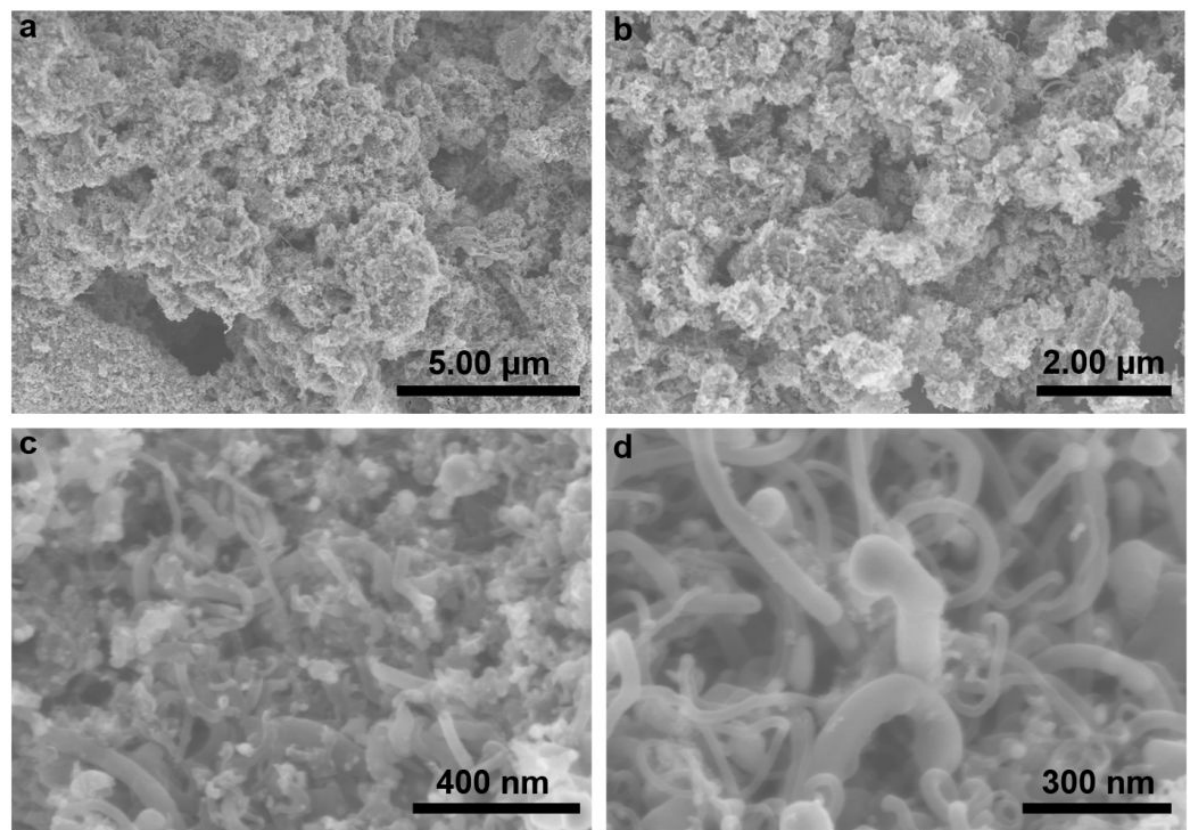

Figure S16. SEM images of NiFeCoW@NC-800-10-4. 

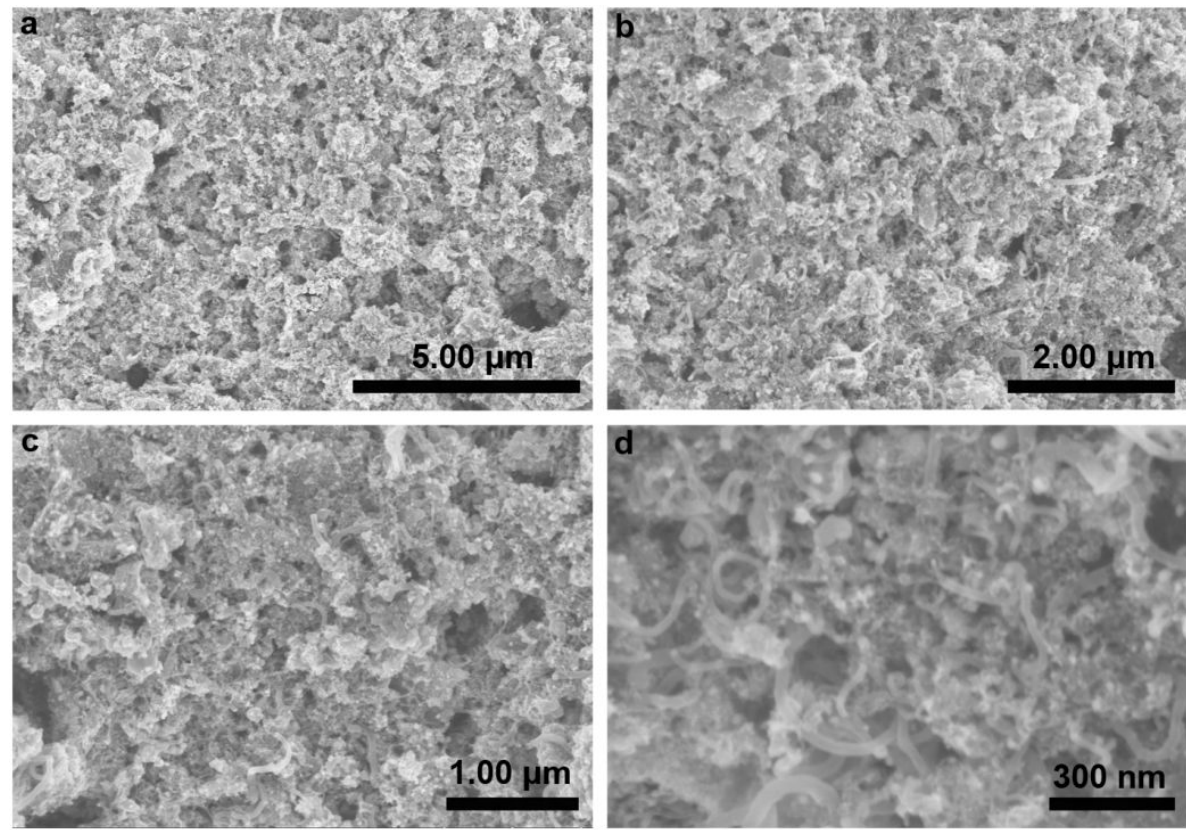

Figure S17. SEM images of NiFeCoW@NC-800-10-6.
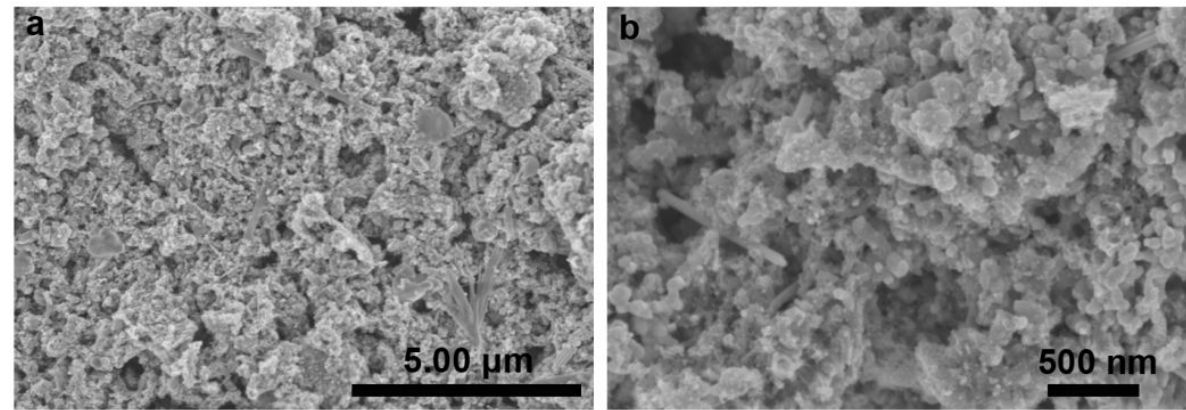

Figure S18. SEM images of p-NiFeCoW@NC.
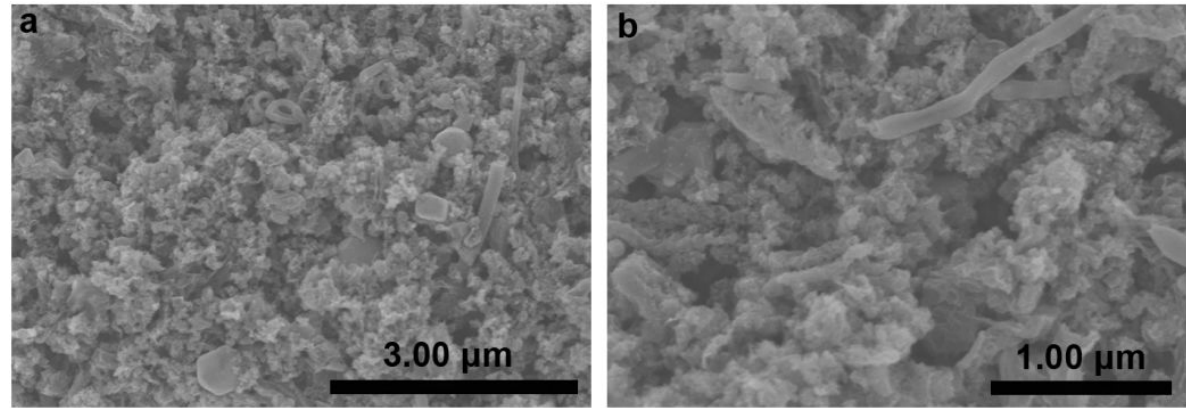

Figure S19. SEM images of NiFe@NC. 

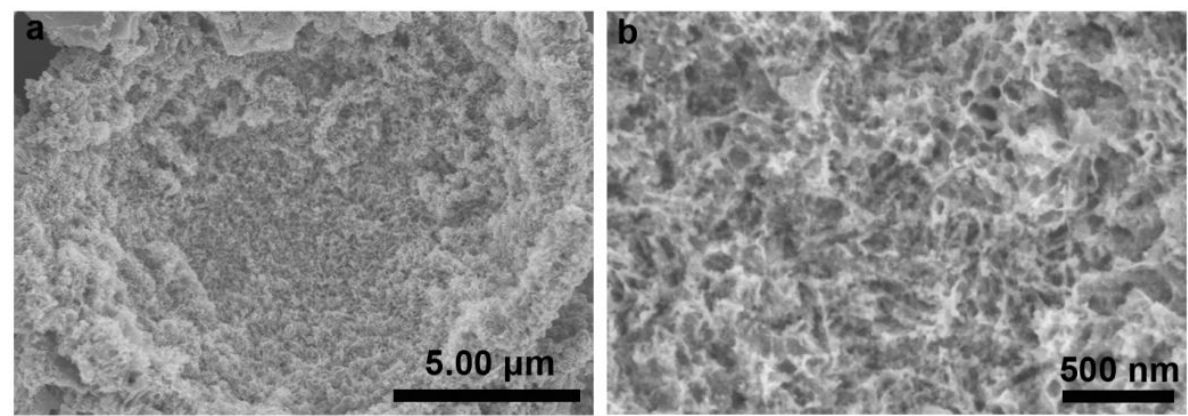

Figure S20. SEM images of CoW@NC.
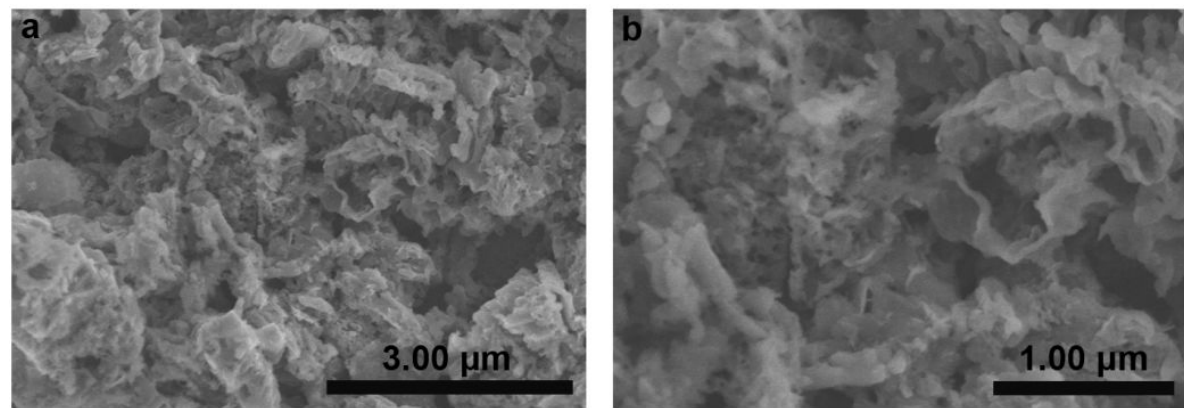

Figure S21. SEM images of NC.
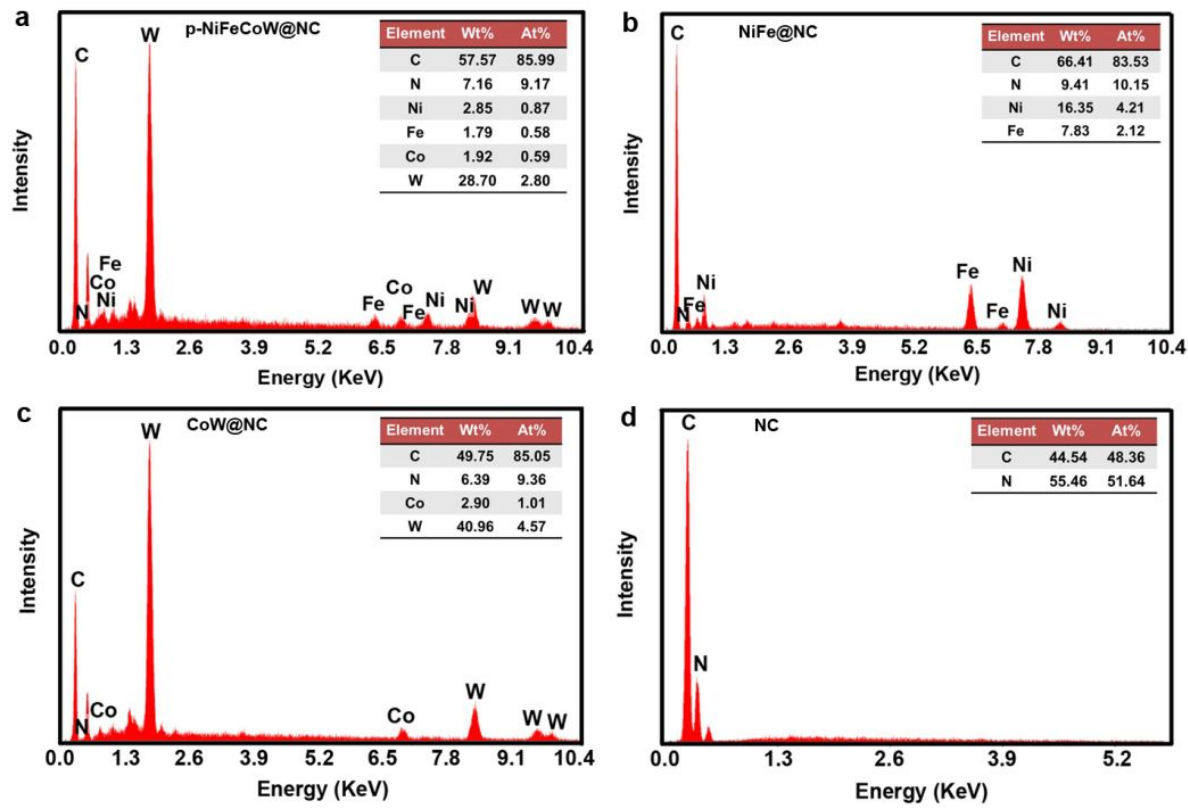

Figure S22. EDS spectrum of p-NiFeCoW@NC, NiFe@NC, CoW@NC and NC. 

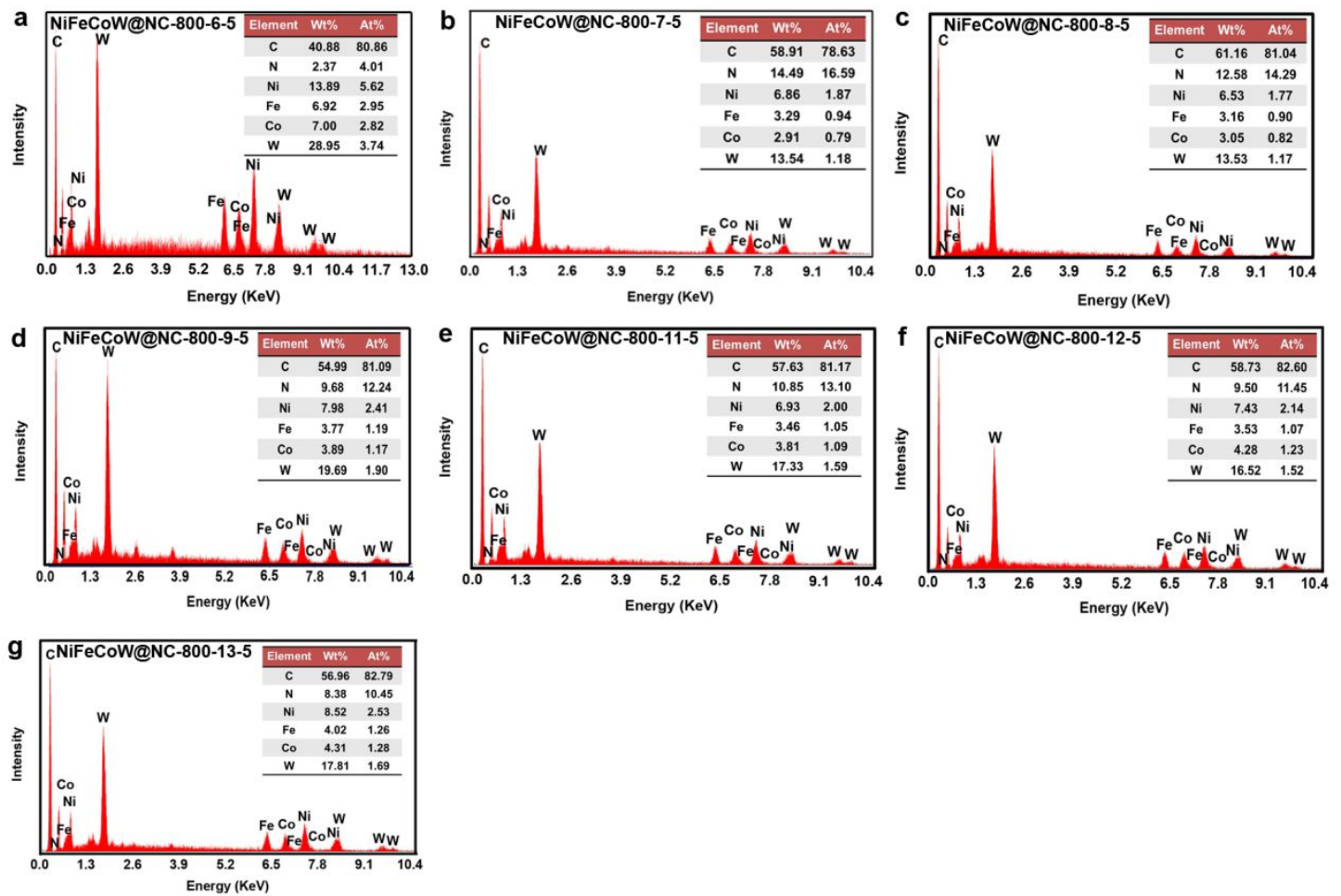

Figure S23. EDS spectrum of NiFeCoW@NC-800-n-5.
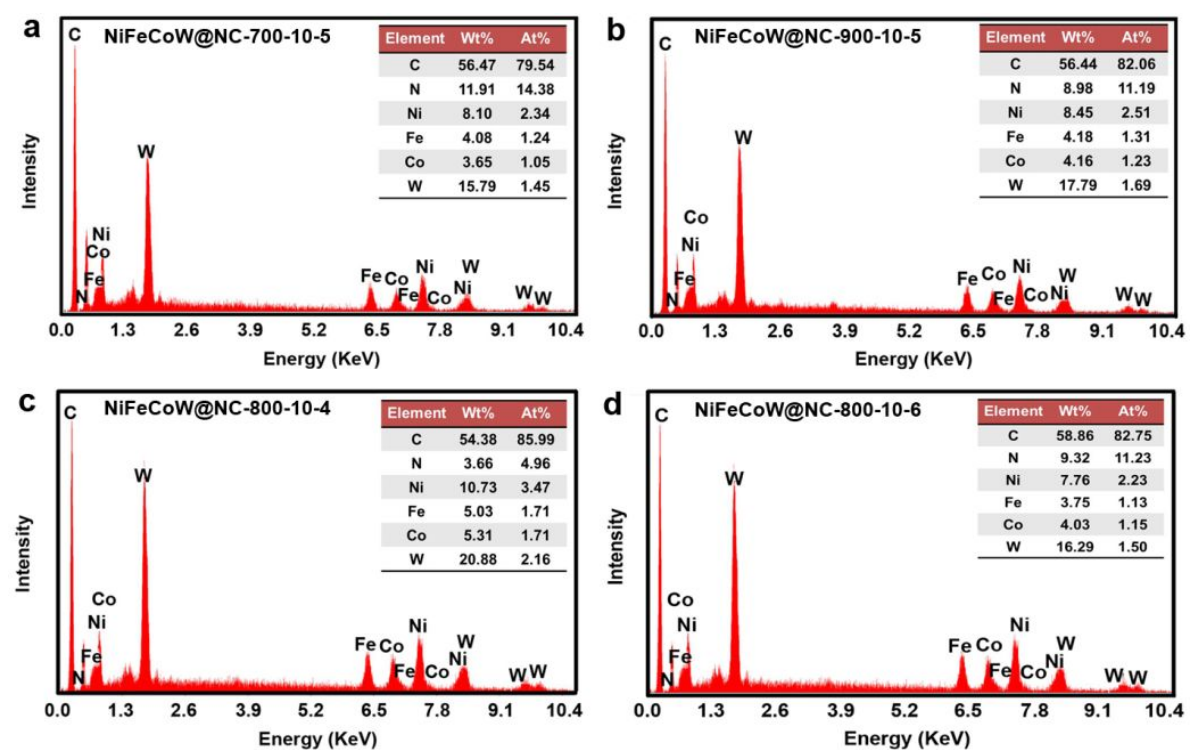

Figure S24. EDS spectrum of NiFeCoW@NC-T-10-5 and NiFeCoW@NC-800-10-t. 

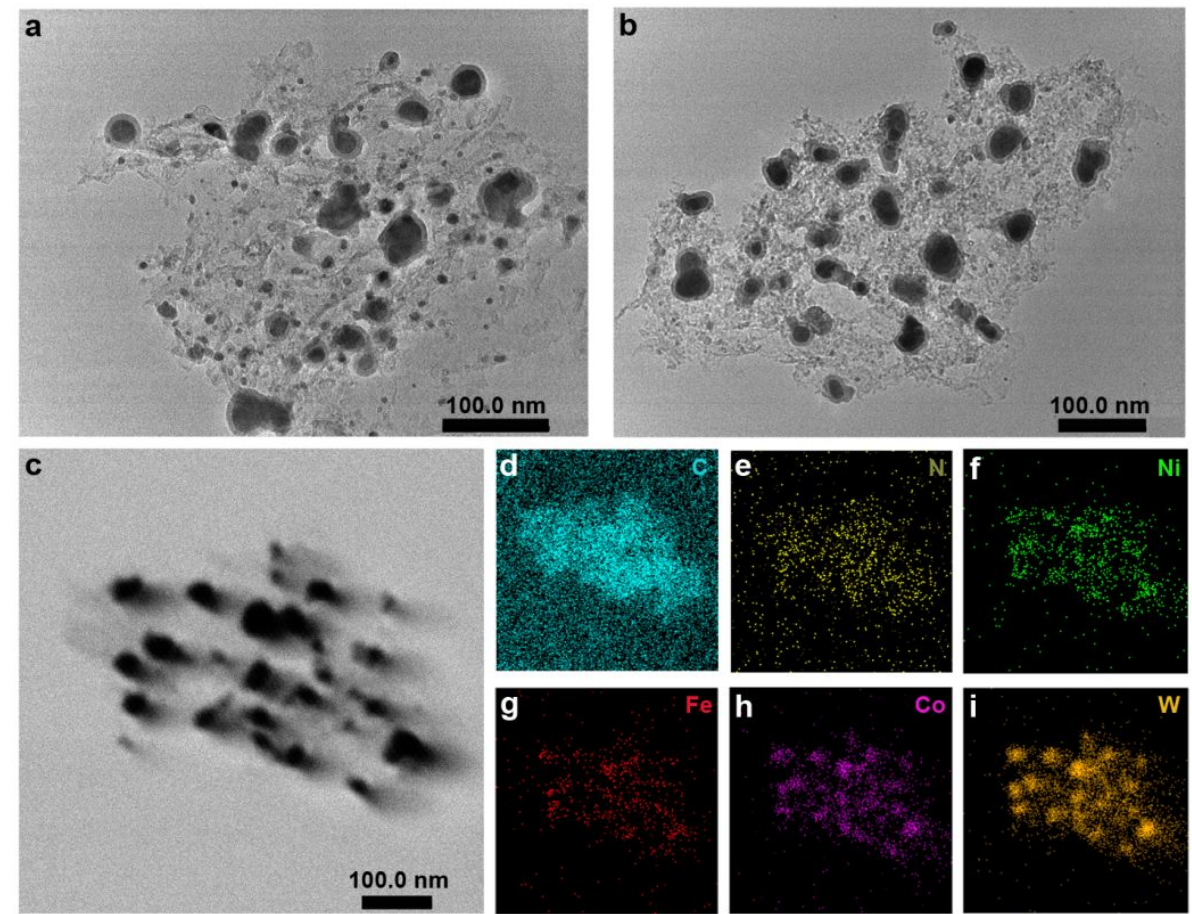

Figure S25. TEM images and the corresponding elemental mapping images of p-NiFeCoW@NC.
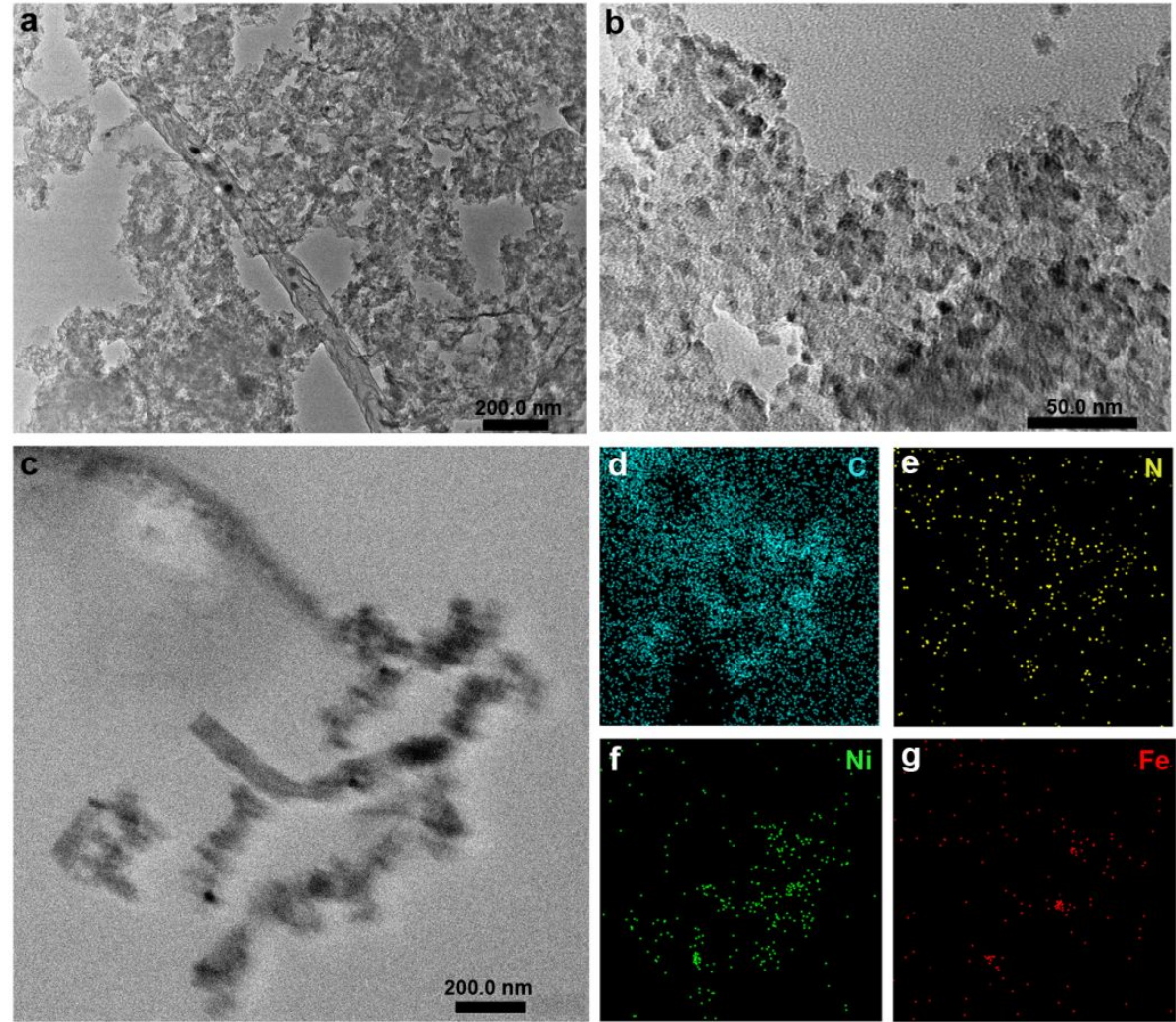

Figure S26. TEM images and the corresponding elemental mapping images of NiFe@NC. 

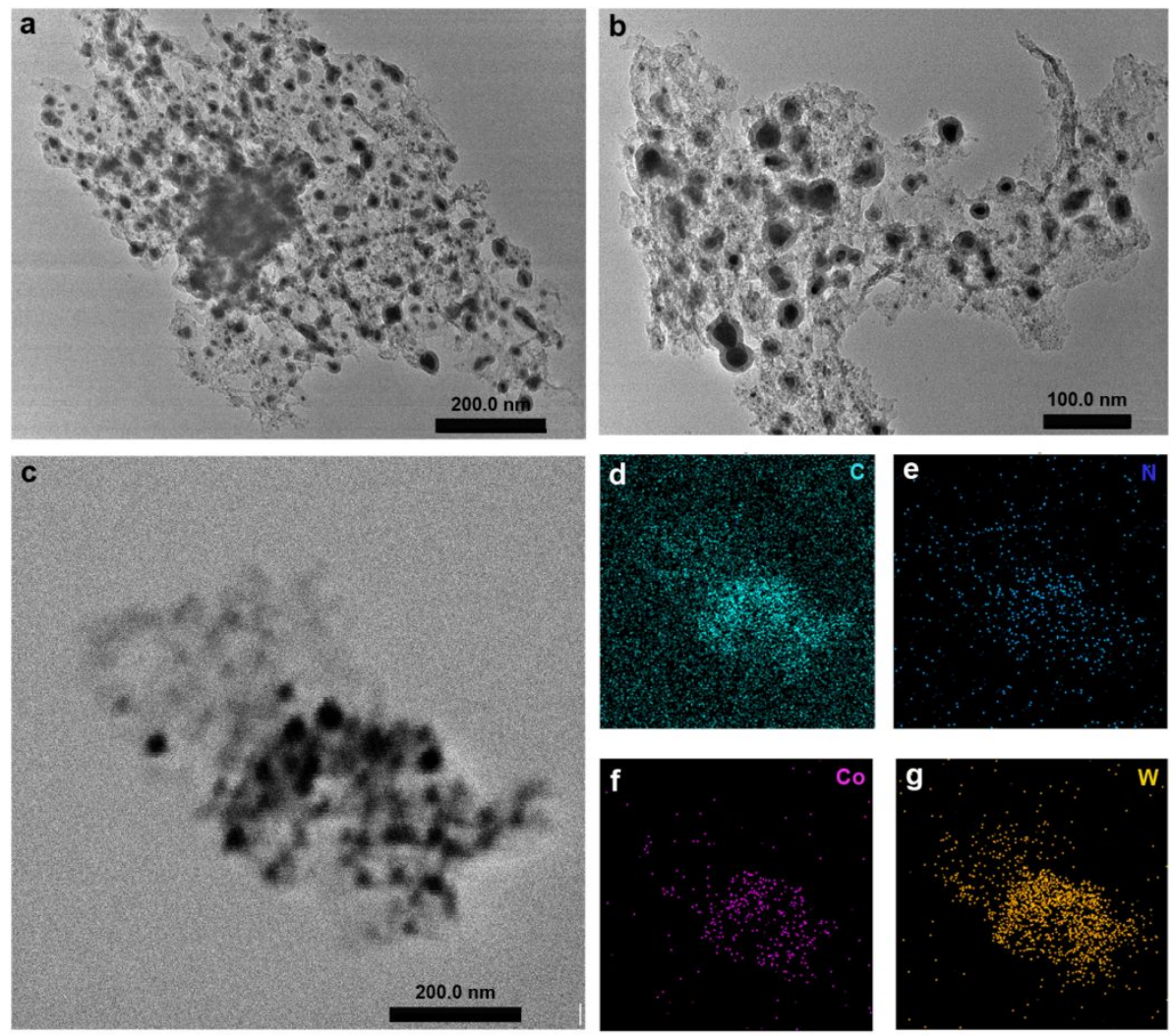

Figure S27. TEM images and the corresponding elemental mapping images of CoW@NC.
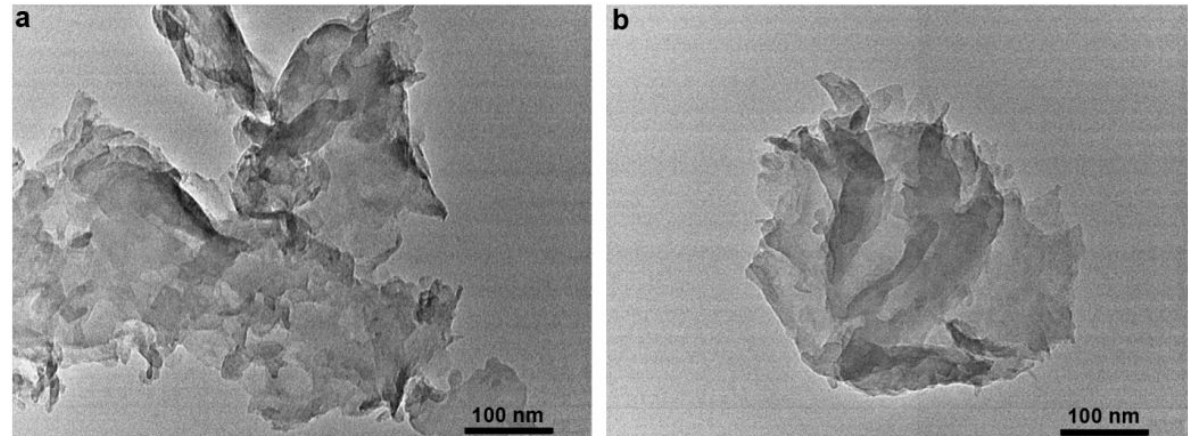

Figure S28. TEM images of NC. 


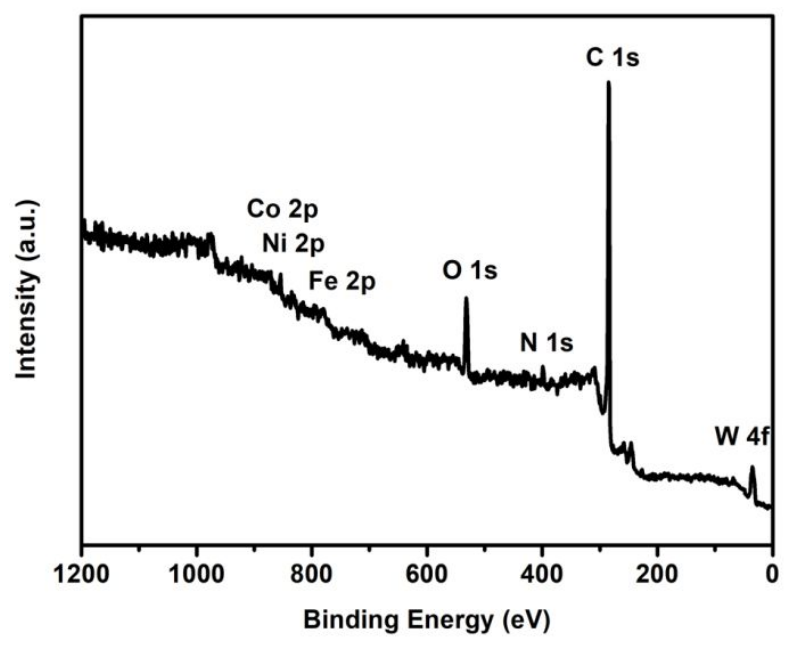

Figure S29. XPS survey spectra of NiFeCoW@NC hybrid. The result reveals that the NiFeCoW@NC is composed of Ni, Fe, Co, W, C and N elements.
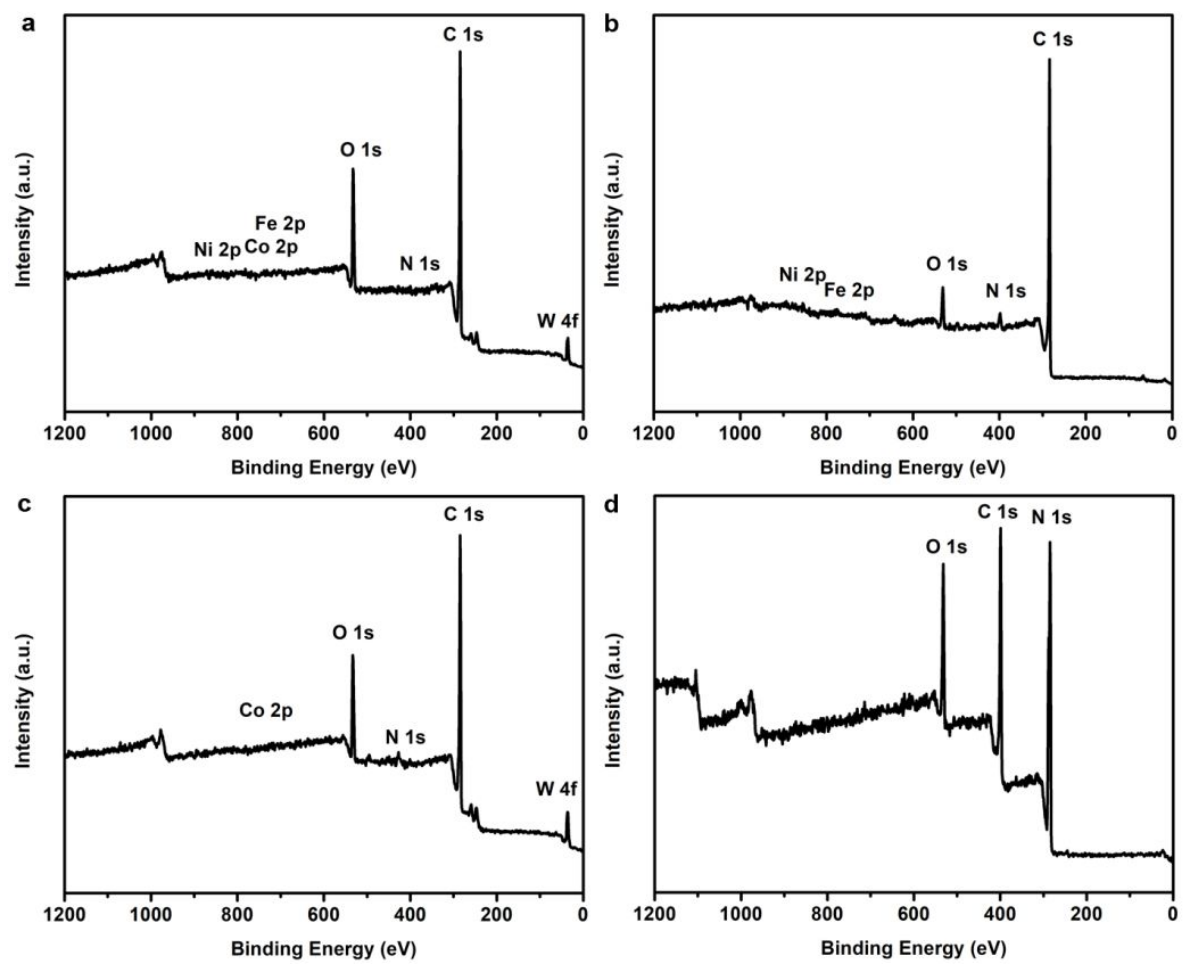

Figure S30. XPS survey spectra of (a) p-NiFeCoW@NC, (b) $\mathrm{NiFe@NC,} \mathrm{(c)}$ CoW@NC and (d) NC. 

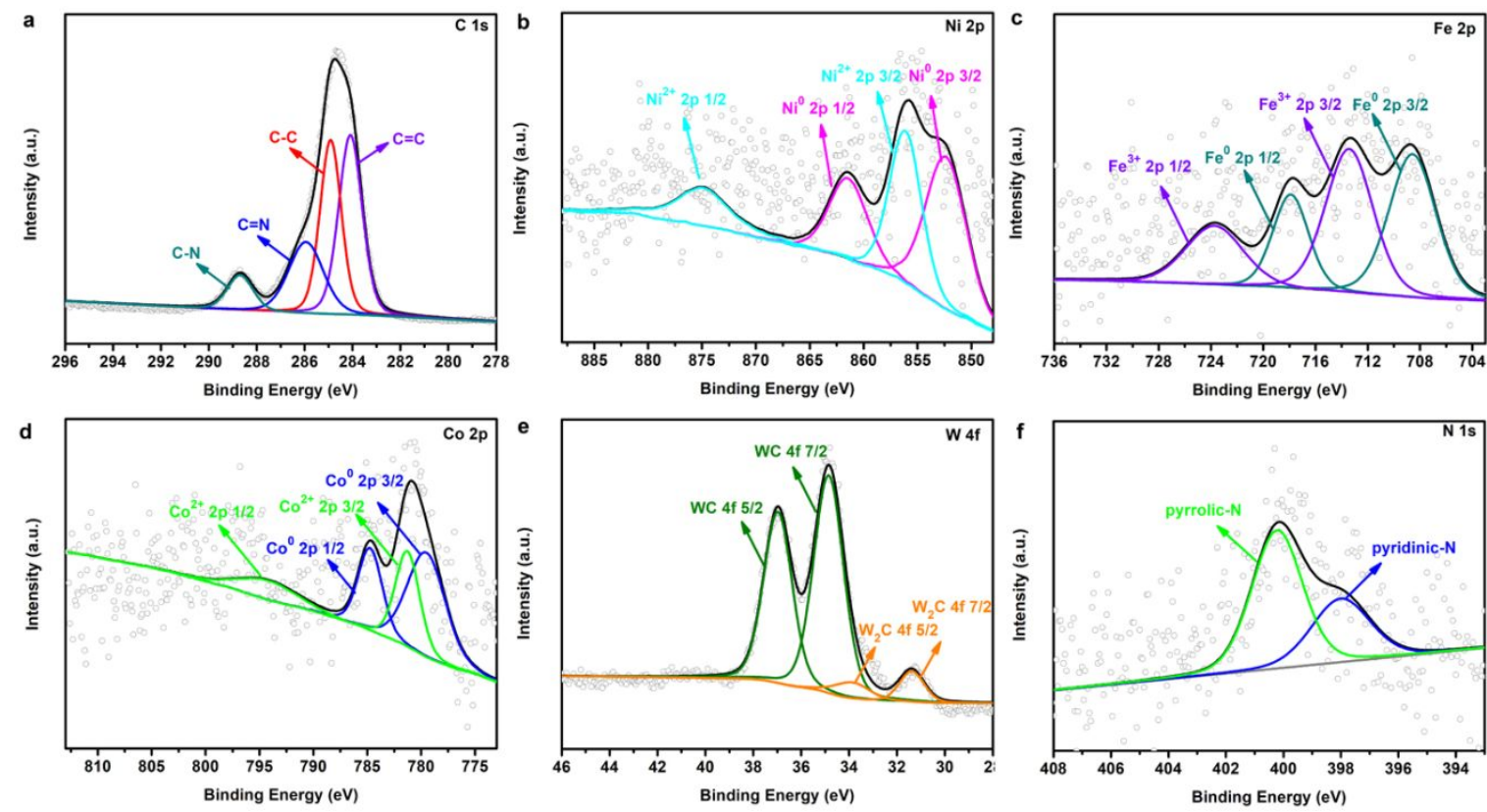

Figure S31. The XPS spectra of (a) C 1s, (b) Ni 2p, (c) Fe 2p, (d) Co 2p, (e) W 4f and (f) N 1s for p-NiFeCoW@NC.
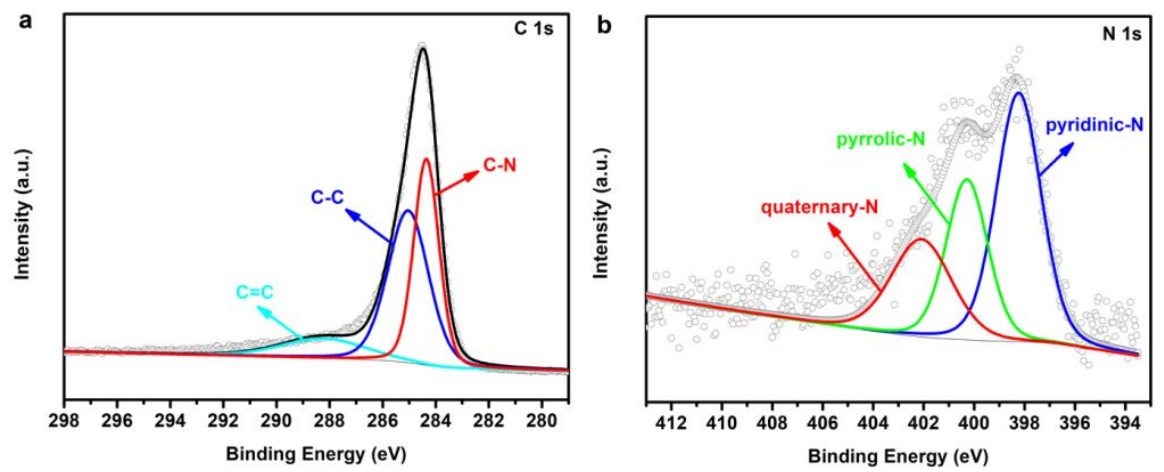

Figure S32. The XPS spectra of (a) C 1s and (b) N 1s for NiFe@NC.
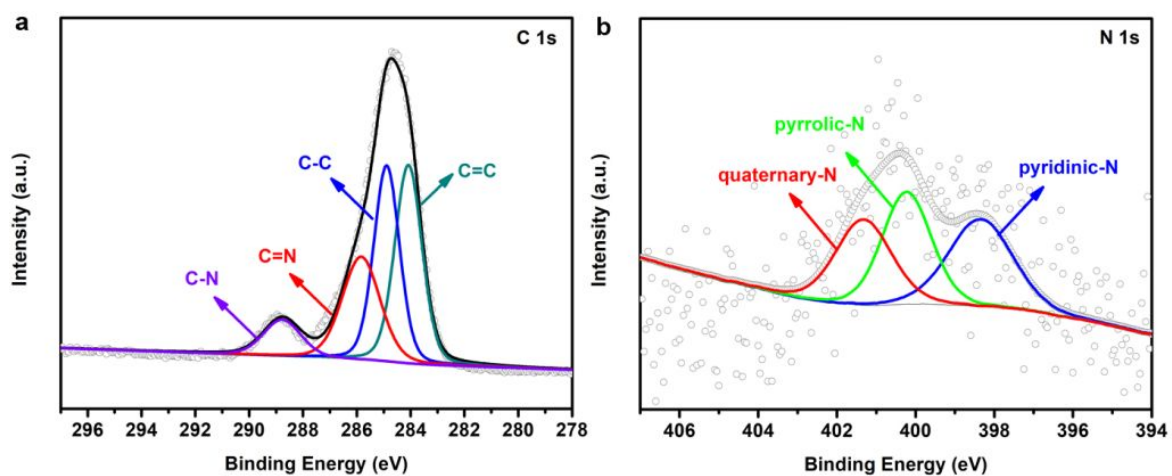

Figure S33. The XPS spectra of (a) C 1s and (b) N 1s for CoW@NC. 

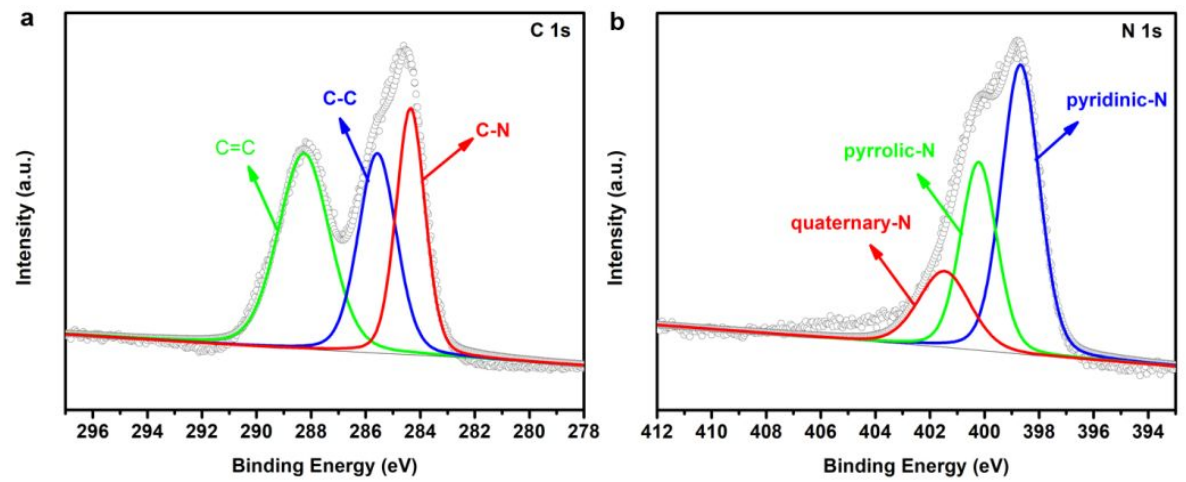

Figure S34. The XPS spectra of (a) C 1s and (b) N 1s for NC.
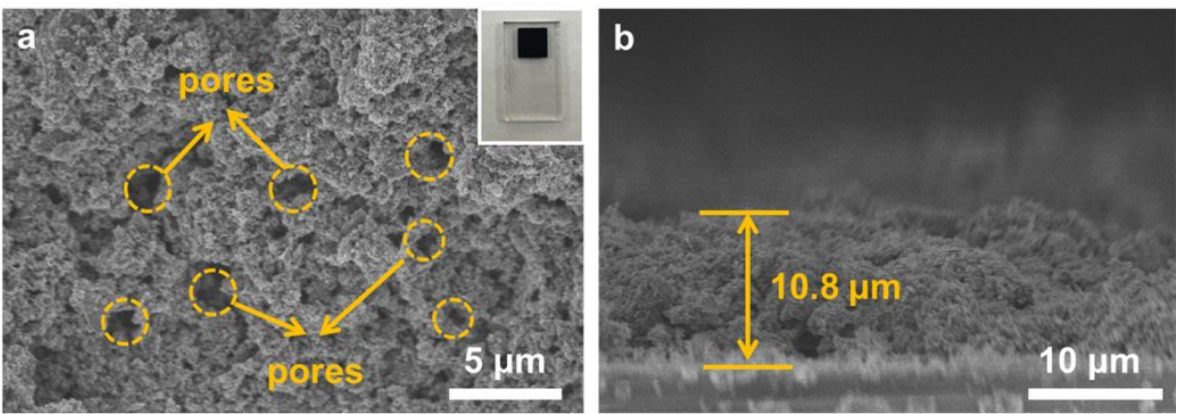

Figure S35. (a) The top-view SEM microscopic images of NiFeCoW@NC CE, inset: the digital photo image of NiFeCoW@NC CE; (b) The cross sectional view SEM microscopic images of the NiFeCoW@NC CE.
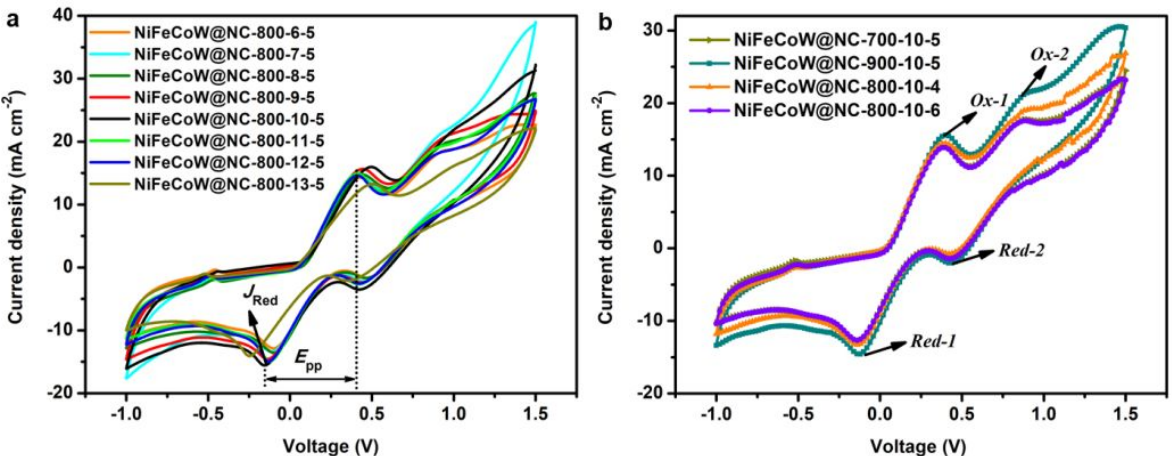

Figure S36. CV curves of (a) NiFeCoW@NC-800-n-5, (b) NiFeCoW@NC-T-10-5 and NiFeCoW@NC-800-10-t. 

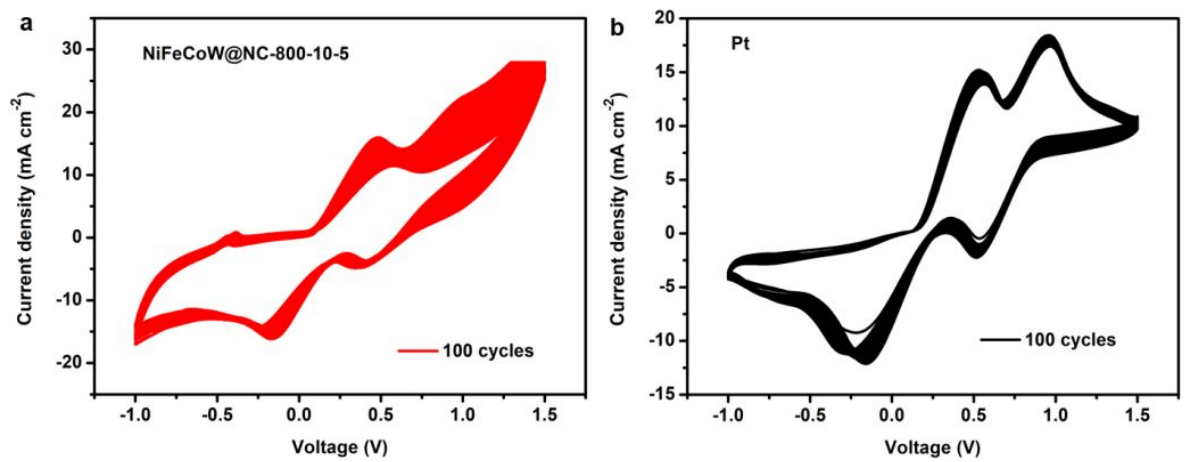

Figure S37. The repeated 100-cycle CV curves of the NiFeCoW@NC and Pt CEs in $\mathrm{I}_{3}{ }^{-/ \mathrm{I}^{-}}$redox electrolyte recorded at a scan rate of $100 \mathrm{mV} \mathrm{s}^{-1}$.
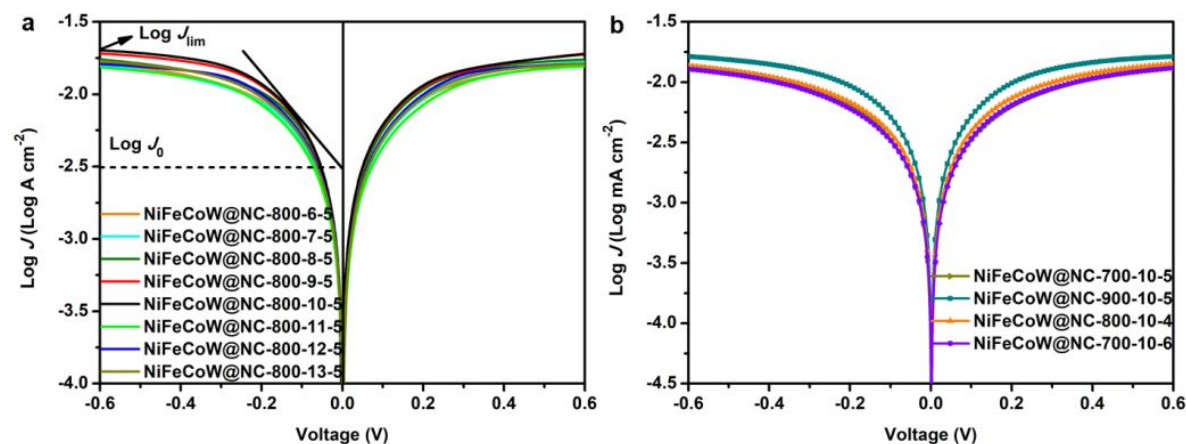

Figure S38. Tafel curves of (a) NiFeCoW@NC-800-n-5, (b) NiFeCoW@NC-T-10-5 and NiFeCoW@NC-800-10-t.
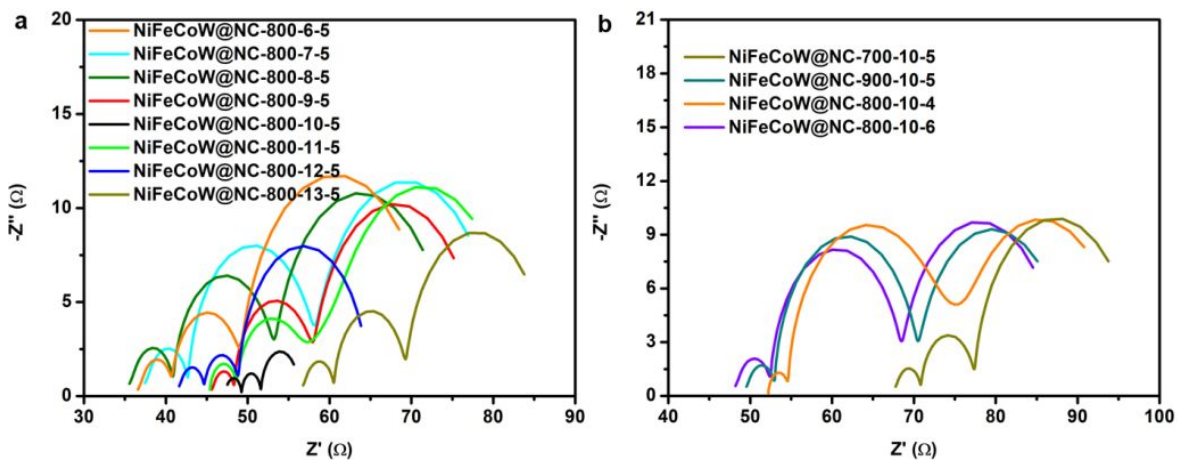

Figure S39. EIS plots of (a) NiFeCoW@NC-800-n-5, (b) NiFeCoW@NC-T-10-5 and NiFeCoW@NC-800-10-t. 


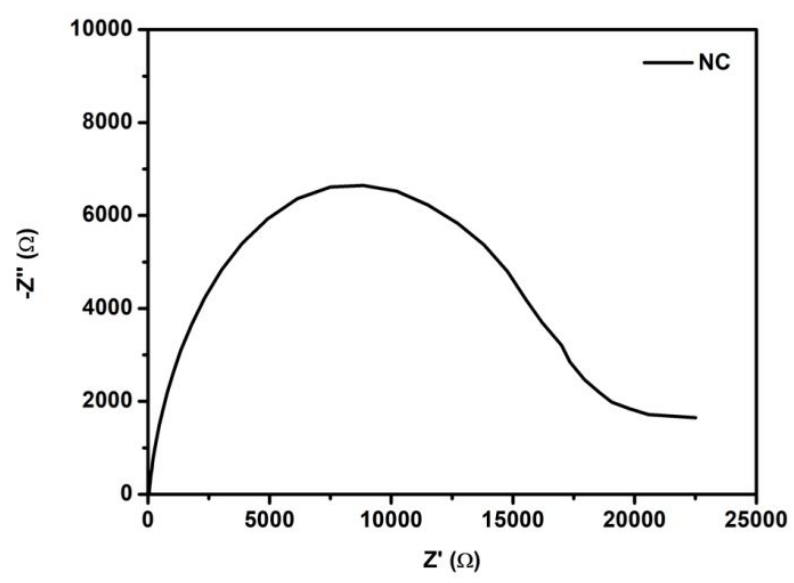

Figure S40. EIS plots of NC CEs.

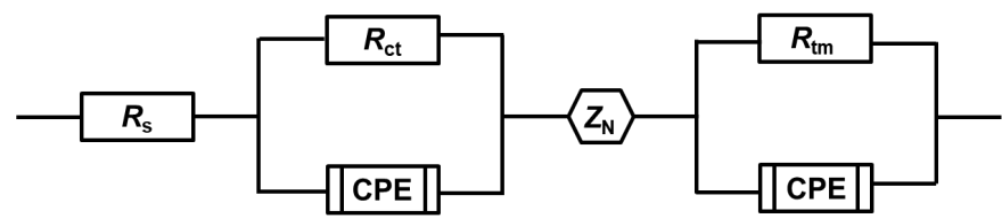

Figure S41. The equivalent circuit for EIS analysis in DSSC; $R_{\mathrm{S}}$ is the series resistance, $R_{\mathrm{tm}}$ is the electron transmission resistance, CPE represents the electrochemistry double-layer capacitance, the charge transfer resistance related to the IRR process is $R_{\mathrm{ct}} ; Z_{\mathrm{N}}$ is the diffusion impedance.
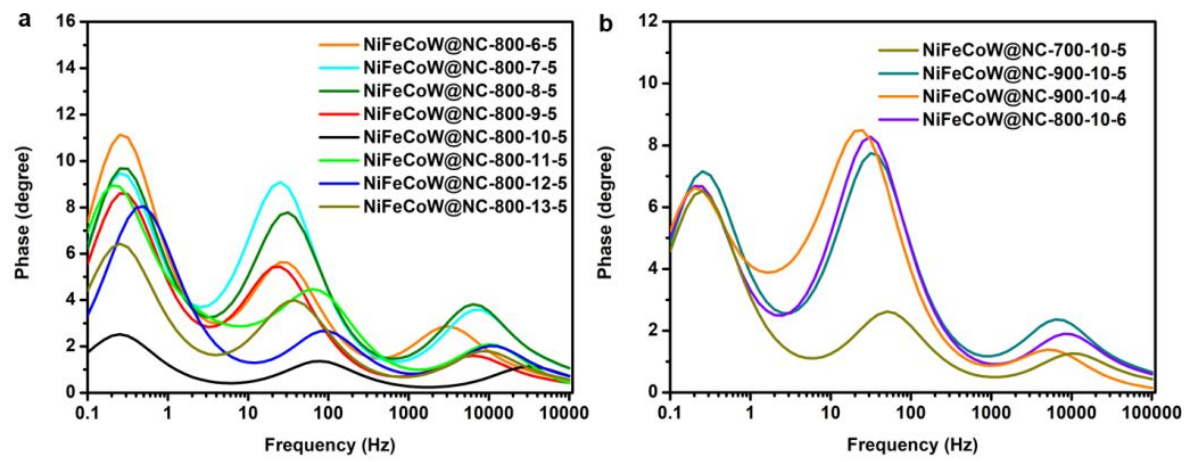

Figure S42. Bode phase plots of (a) NiFeCoW@NC-800-n-5, (b) NiFeCoW@NC-T-10-5 and NiFeCoW@NC-800-10-t. 


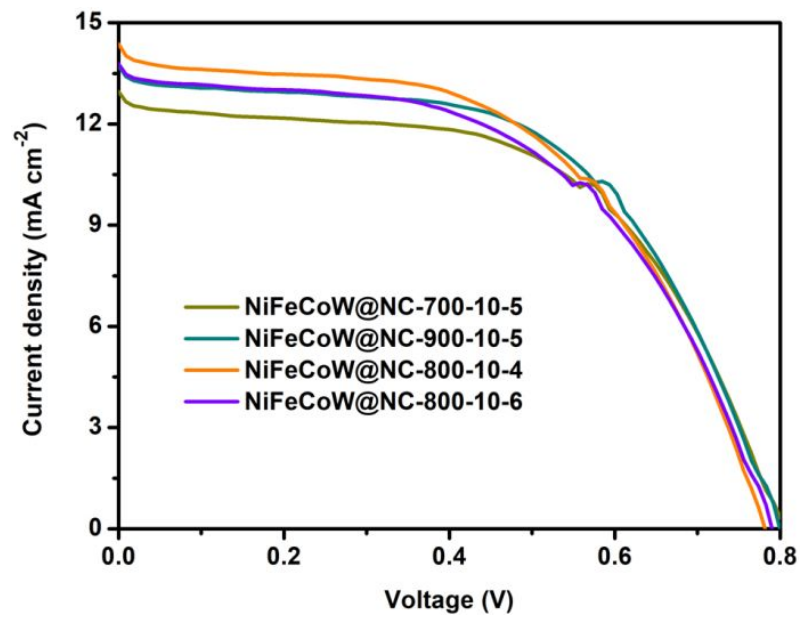

Figure S43. J- $V$ curves of NiFeCoW@NC-T-10-5 and NiFeCoW@NC-800-10-t.
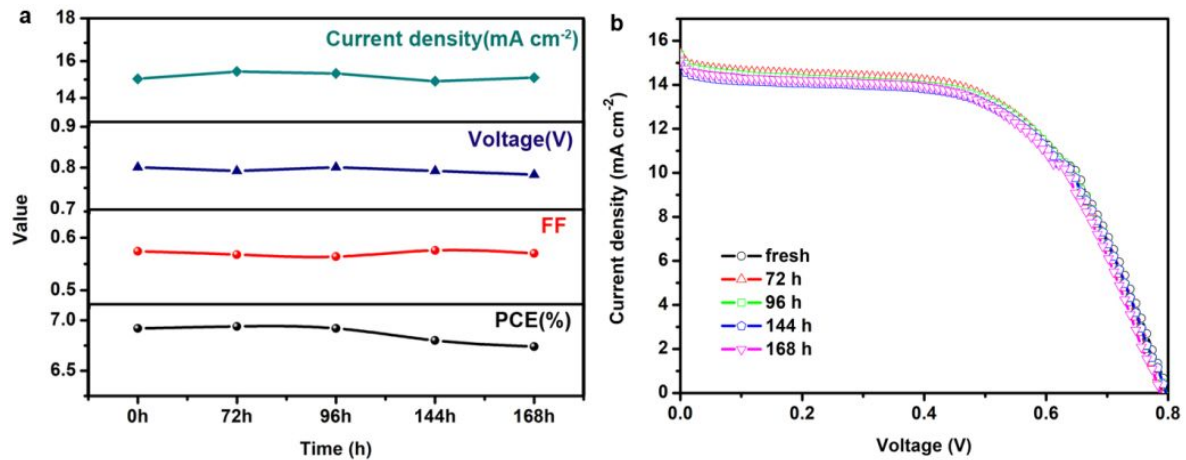

Figure S44. Long-term stability of a DSSC based on NiFeCoW@NC-800-10-5 CE. (a) The current density, voltage, $F F$ and $P C E$ values and (b) $J-V$ curves of DSSCs at different test times. 

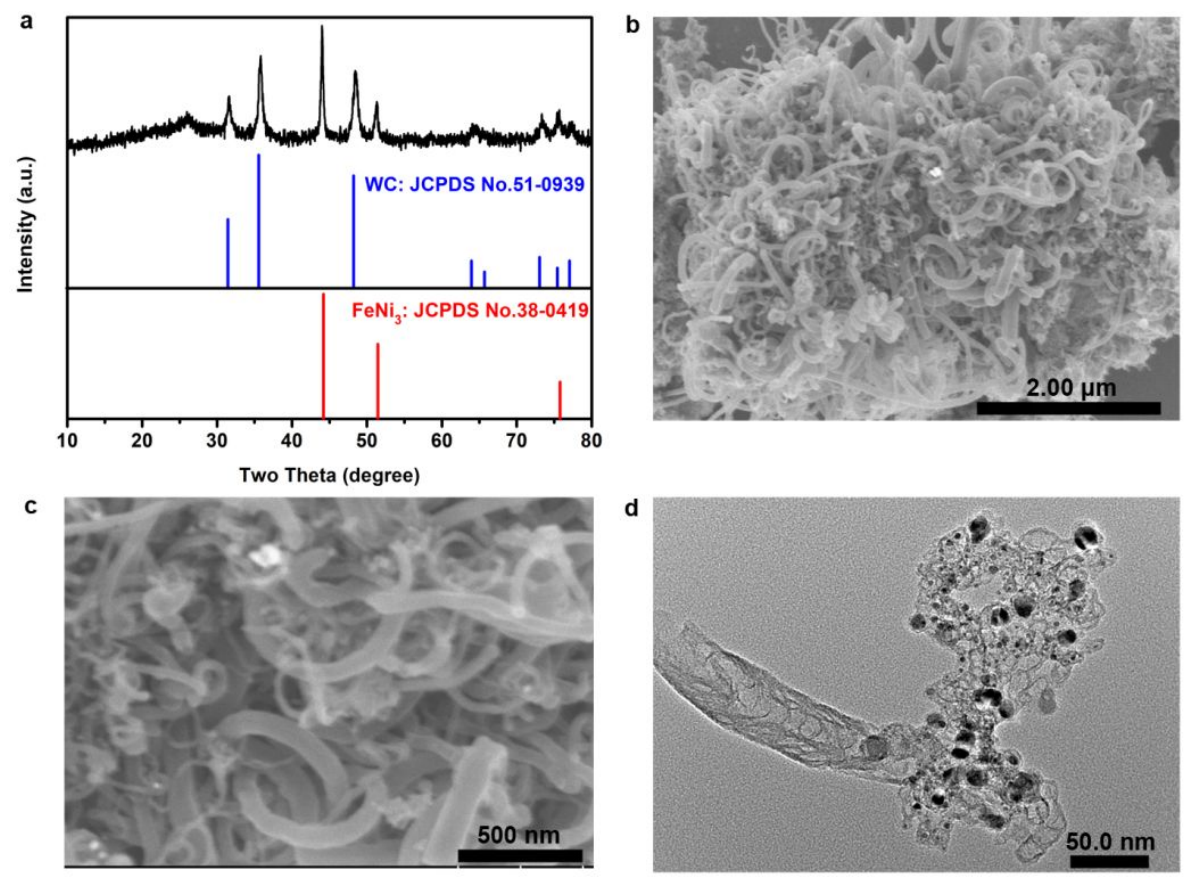

Figure S45. (a) XRD pattern, (b), (c) SEM images and (d) TEM images of NiFeCoW@NC after stability test in DSSCs.
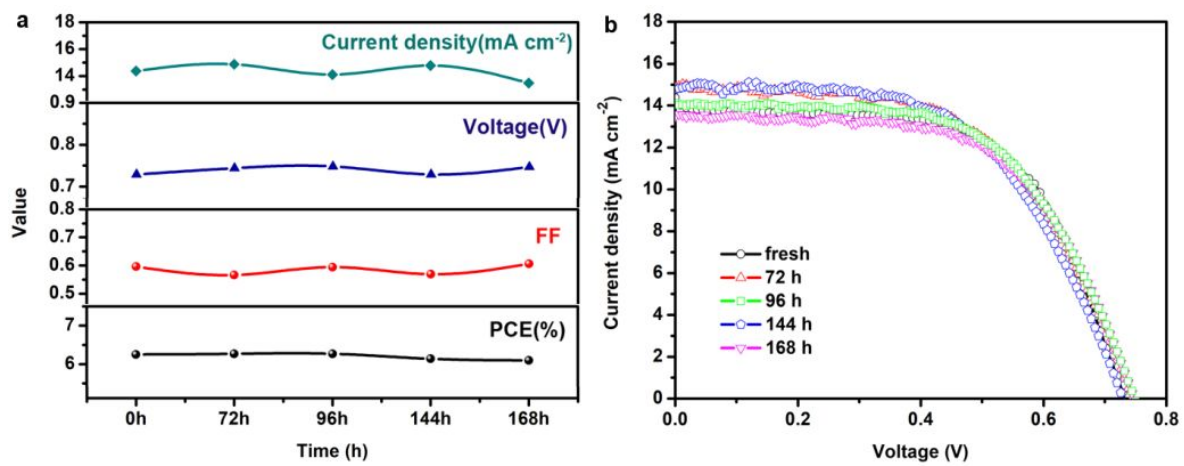

Figure S46. Long-term stability of a DSSC based on Pt CE. (a) The current density, voltage, $F F$ and $P C E$ values and (b) $J-V$ curves of DSSCs at different test times. 


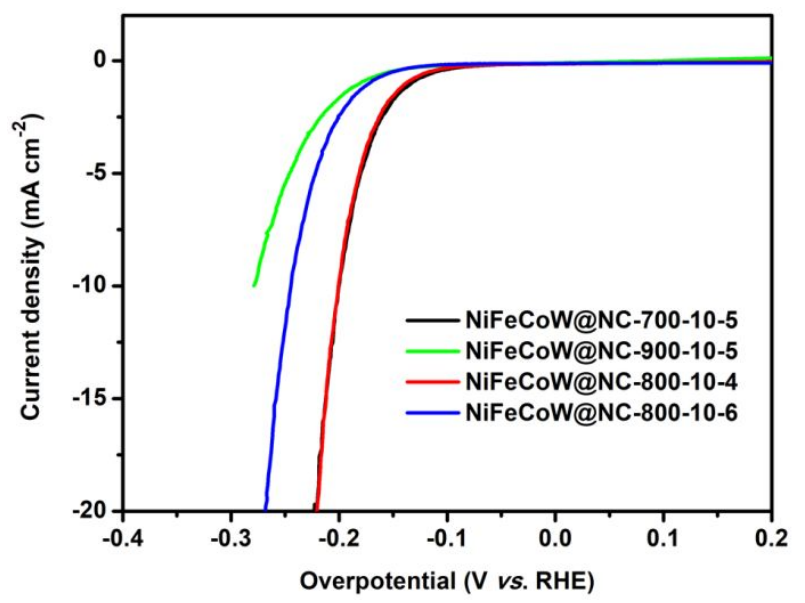

Figure S47. LSV polarization curves of NiFeCoW@NC-T-10-5 and NiFeCoW@NC-800-10-t.

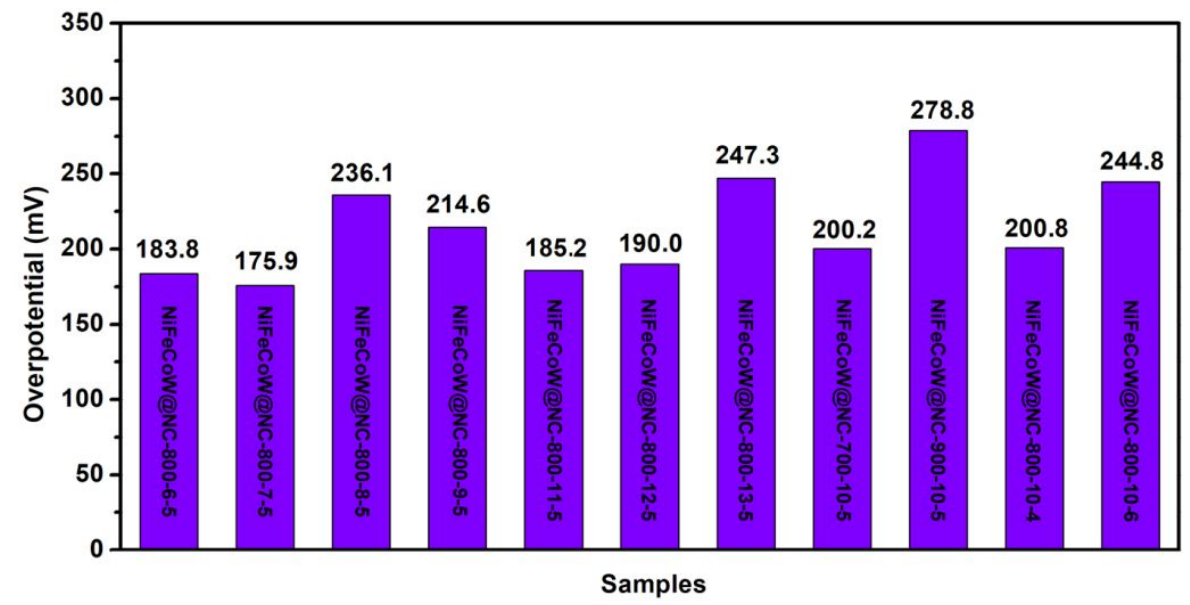

Figure S48. The overpotentials of NiFeCoW@NC-800-n-5, NiFeCoW@NC-T-10-5 and NiFeCoW@NC-800-10-t. 

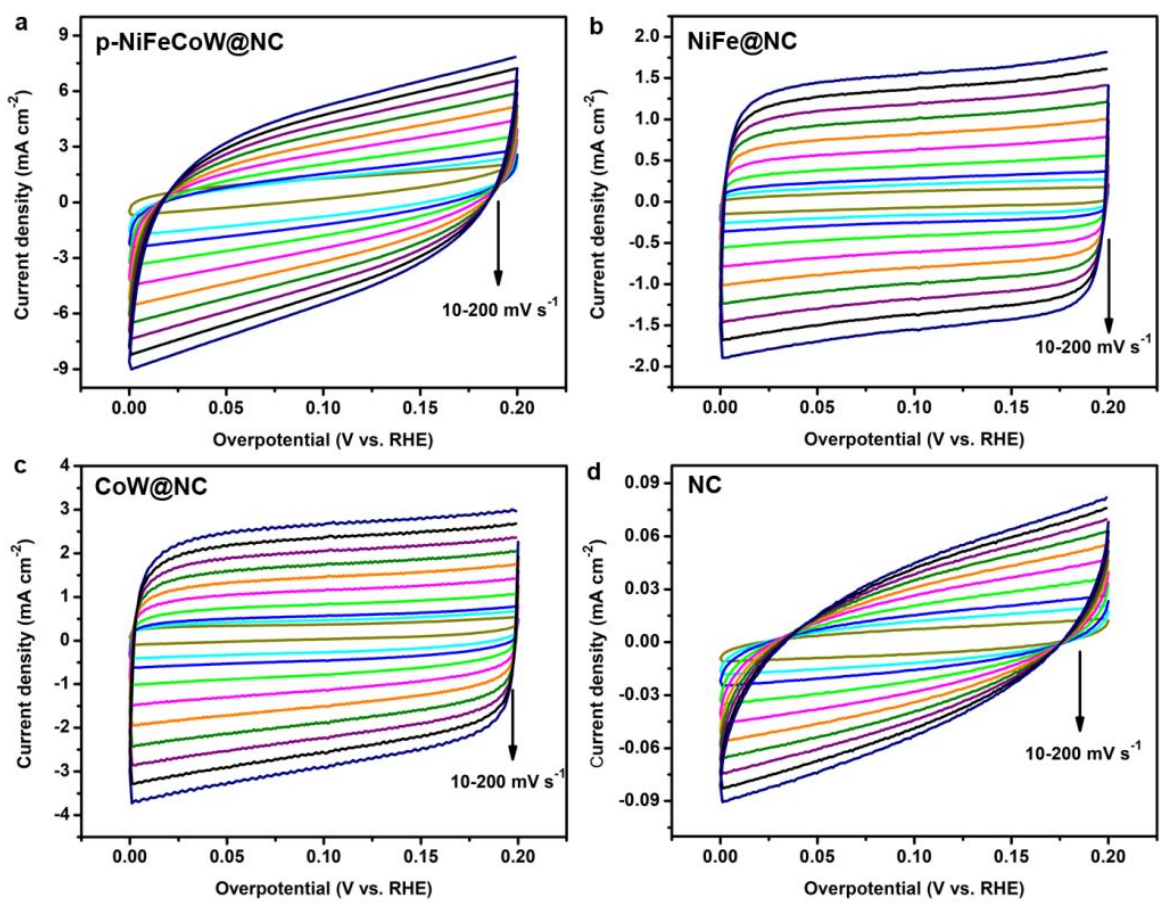

Figure S49. CV curves of p-NiFeCoW@NC, NiFe@NC, CoW@NC and NC in 0.5 $\mathrm{M} \mathrm{H}_{2} \mathrm{SO}_{4}$ electrolyte at different scan rates.
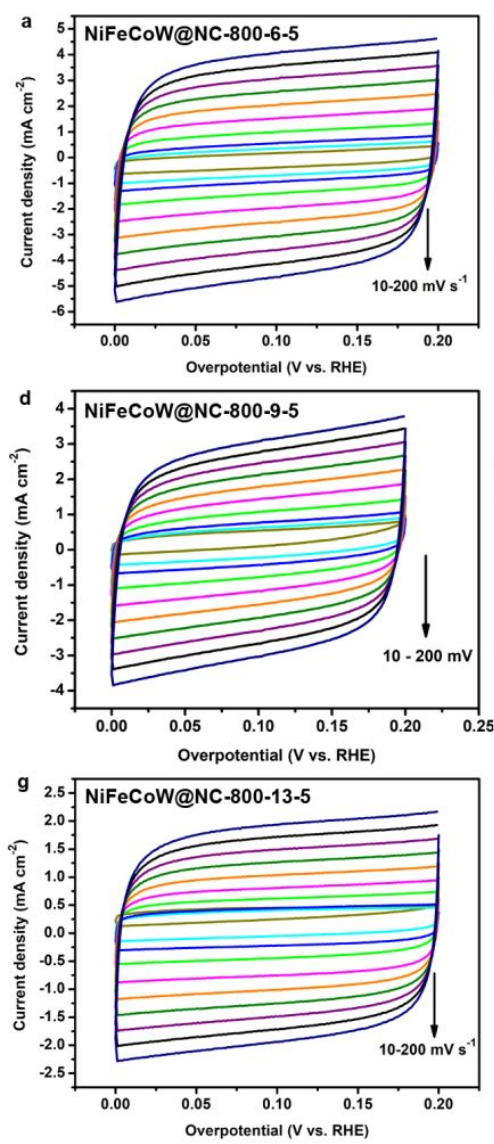
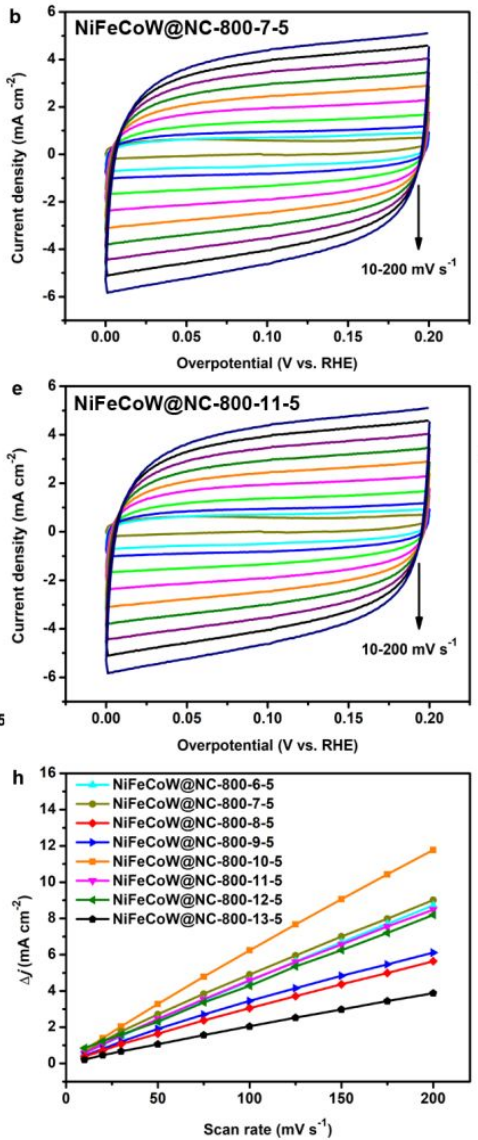
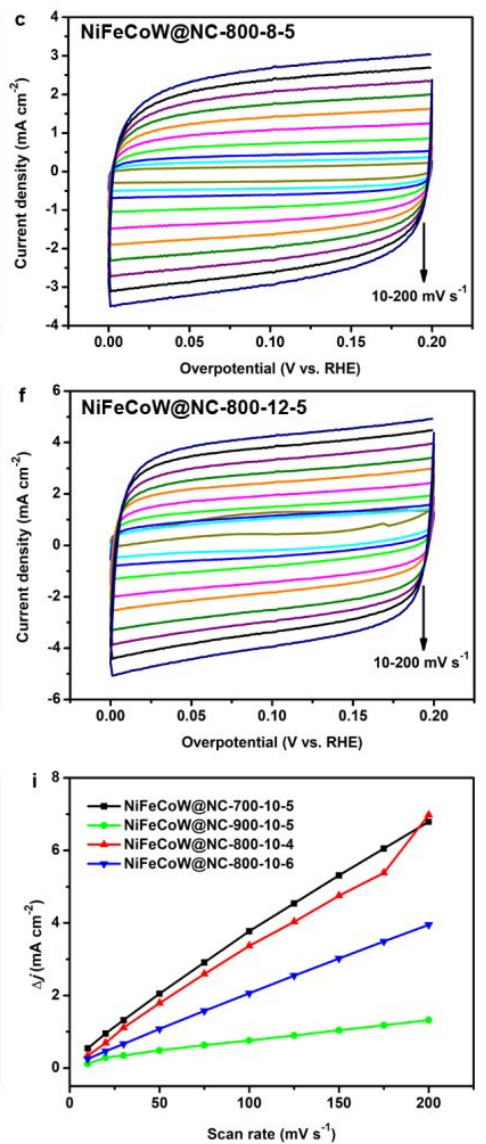

Figure S50. (a-g) CV curves of NiFeCoW@NC-800-n-5 in $0.5 \mathrm{M} \mathrm{H}_{2} \mathrm{SO}_{4}$ electrolyte 
at different scan rates; (h) $C_{\mathrm{dl}}$ values of NiFeCoW@NC-800-n-5; and (i) $C_{\mathrm{dl}}$ values of NiFeCoW@NC-T-10-5 and NiFeCoW@NC-800-10-t.
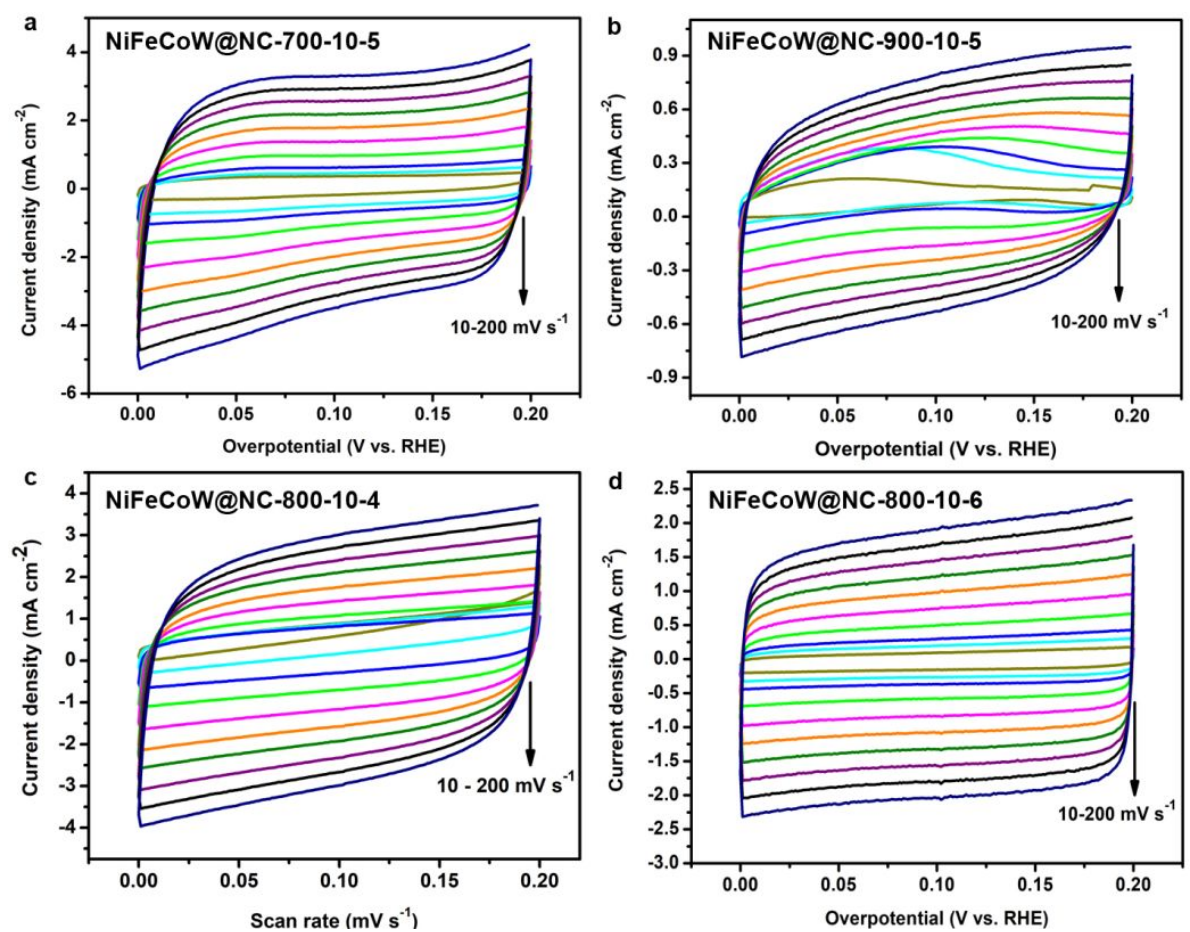

Figure S51. CV curves of NiFeCoW@NC-T-10-t in $0.5 \mathrm{M} \mathrm{H}_{2} \mathrm{SO}_{4}$ electrolyte at different scan rates.

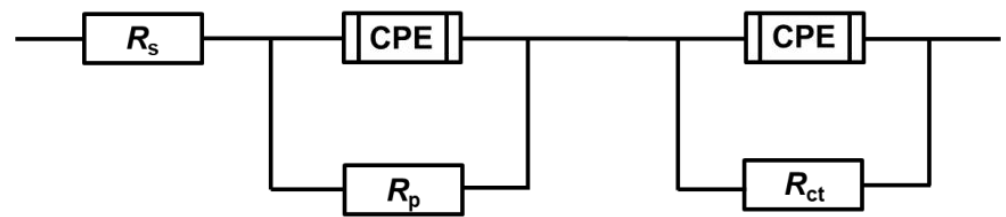

Figure S52. The equivalent circuit for HER; $R_{\mathrm{S}}$ is the series resistance, the resistance related to the surface porosity is depicted with $R_{\mathrm{p}}$, and the charge transfer resistance related to the HER process is $R_{\mathrm{ct}}$. CPE represents the constant phase elements. 


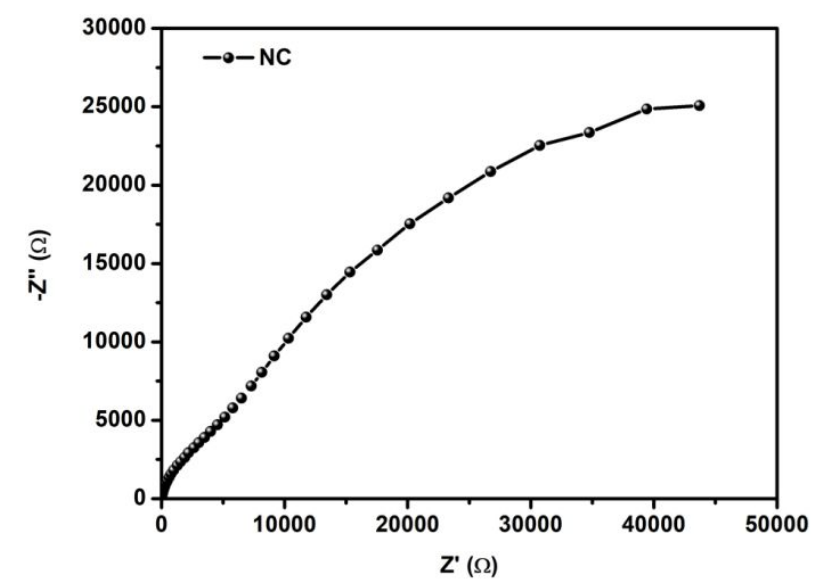

Figure S53. EIS plots of $\mathrm{NC}$ measured in $0.5 \mathrm{M} \mathrm{H}_{2} \mathrm{SO}_{4}$.

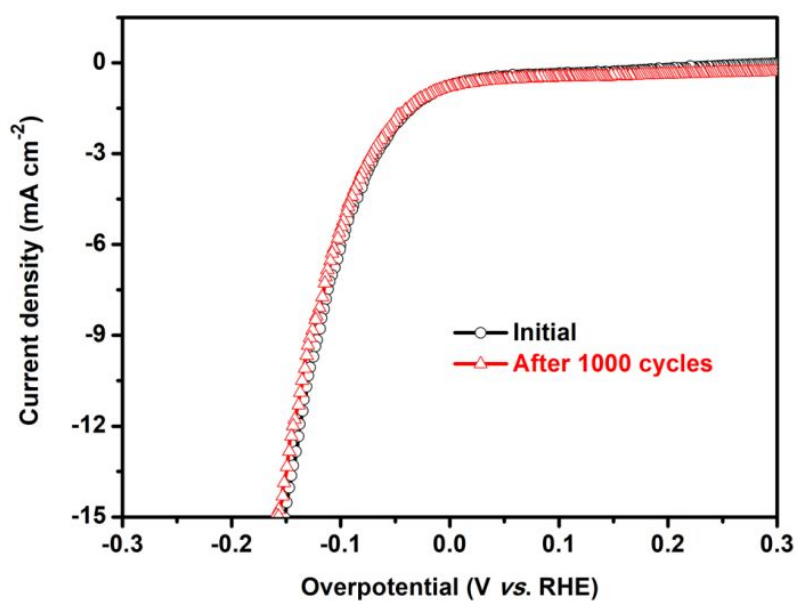

Figure S54. Polarization curves of NiFeCoW@NC initially and after 1000 cycles in $0.5 \mathrm{M} \mathrm{H}_{2} \mathrm{SO}_{4}$ at a scan rate of $5 \mathrm{mV} \mathrm{s}^{-1}$. 

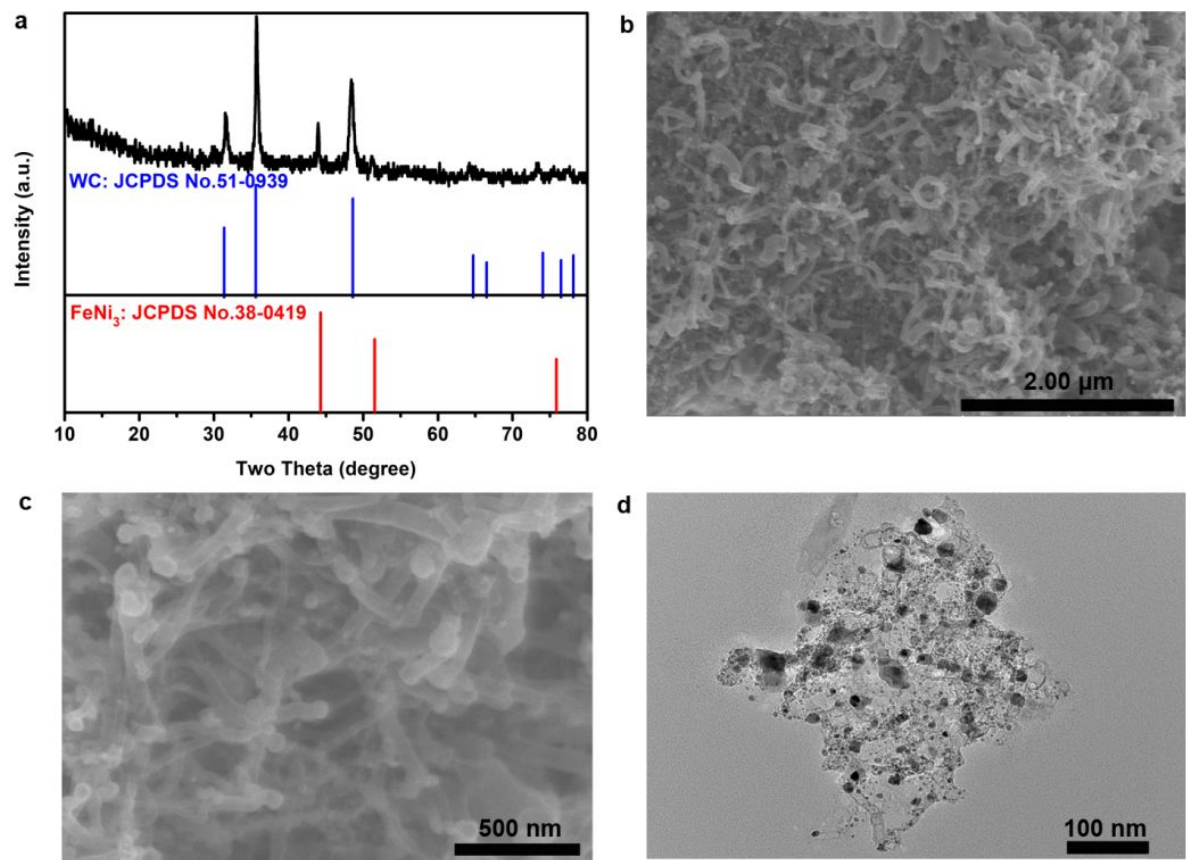

Figure S55. (a) XRD pattern, (b), (c) SEM images and (d) TEM images of NiFeCoW@NC after tests in HER.
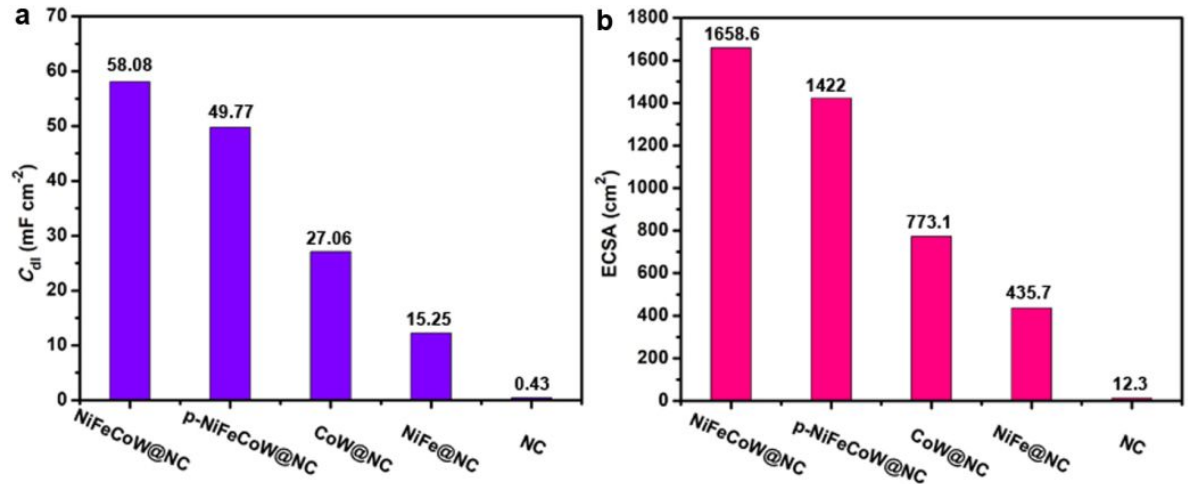

Figure S56. (a) $C_{\mathrm{dl}}$ values and (b) ECSA values of NiFeCoW@NC, p-NiFeCoW@NC,NiFe@NC, CoW@NC and NC. 
Table S1. The electrochemical parameters of different NiFeCoW@NC-T-n-t CEs.

\begin{tabular}{lcccc}
\hline $\mathrm{CE}$ & $J_{\text {red }}\left(\mathrm{mA} \mathrm{cm}^{-2}\right)$ & $E_{\mathrm{pp}}(\mathrm{mV})$ & $\log J_{\lim }\left(\mathrm{mA} \mathrm{cm}^{-2}\right)$ & $\log J_{0}\left(\mathrm{~mA} \mathrm{~cm}^{-2}\right)$ \\
\hline NiFeCoW@NC-800-6-5 & 12.93 & 540 & -1.46 & -2.65 \\
NiFeCoW@NC-800-7-5 & 13.43 & 533 & -1.45 & -2.66 \\
NiFeCoW@NC-800-8-5 & 13.61 & 542 & -1.41 & -2.58 \\
NiFeCoW@NC-800-9-5 & 14.62 & 576 & -1.37 & -2.56 \\
NiFeCoW@NC-800-11-5 & 14.94 & 534 & -1.48 & -2.69 \\
NiFeCoW@NC-800-12-5 & 14.97 & 541 & -1.41 & -2.62 \\
NiFeCoW@NC-800-13-5 & 14.11 & 755 & -1.43 & -2.64 \\
NiFeCoW@NC-700-10-5 & 12.99 & 532 & -1.59 & -2.68 \\
NiFeCoW@NC-900-10-5 & 14.80 & 528 & -1.45 & -2.48 \\
NiFeCoW@NC-800-10-4 & 13.36 & 523 & -1.53 & -2.62 \\
NiFeCoW@NC-800-10-6 & 12.70 & 528 & -1.58 & -2.70 \\
\hline
\end{tabular}

Table S2. Summarized parameters of EIS measurements for NiFeCoW@NC-T-n-t CEs.

\begin{tabular}{lcccc}
\hline CE & $R_{\mathrm{s}}(\Omega)$ & $R_{\mathrm{ct}}(\Omega)$ & $R_{\mathrm{tm}}(\Omega)$ & $Z_{\mathrm{N}}$ \\
\hline NiFeCoW@NC-800-6-5 & 36.25 & 23.37 & 8.42 & 2.59 \\
NiFeCoW@NC-800-7-5 & 36.78 & 15.52 & 22.53 & 1.29 \\
NiFeCoW@NC-800-8-5 & 34.90 & 12.39 & 21.38 & 1.35 \\
NiFeCoW@NC-800-9-5 & 45.27 & 20.24 & 9.69 & 2.61 \\
NiFeCoW@NC-800-11-5 & 45.36 & 3.43 & 7.42 & 56.03 \\
NiFeCoW@NC-800-12-5 & 41.20 & 4.17 & 15.91 & 1.71 \\
NiFeCoW@NC-800-13-5 & 56.20 & 17.33 & 8.80 & 1.57 \\
NiFeCoW@NC-700-10-5 & 67.25 & 6.58 & 19.78 & 1.72 \\
NiFeCoW@NC-900-10-5 & 47.64 & 19.19 & 16.05 & 1.61 \\
NiFeCoW@NC-800-10-4 & 52.21 & 2.58 & 17.91 & 65.44 \\
NiFeCoW@NC-800-10-6 & 49.04 & 17.53 & 18.36 & 1.73 \\
\hline
\end{tabular}


Table S3. The photovoltaic parameters of DSSCs based on NiFeCoW@NC-T-n-t CEs.

\begin{tabular}{lcccc}
\hline CE & $J_{\mathrm{sc}}\left(\mathrm{mA} \mathrm{cm}^{-2}\right)$ & $V_{\text {oc }}(\mathrm{V})$ & $F F$ & $P C E$ \\
\hline NiFeCoW@NC-800-6-5 & 13.53 & 0.774 & 0.547 & $5.73 \%$ \\
NiFeCoW@NC-800-7-5 & 13.79 & 0.774 & 0.553 & $5.90 \%$ \\
NiFeCoW@NC-800-8-5 & 13.75 & 0.783 & 0.549 & $5.91 \%$ \\
NiFeCoW@NC-800-9-5 & 14.03 & 0.792 & 0.562 & $6.24 \%$ \\
NiFeCoW@NC-800-11-5 & 14.99 & 0.774 & 0.557 & $6.46 \%$ \\
NiFeCoW@NC-800-12-5 & 14.63 & 0.774 & 0.544 & $6.16 \%$ \\
NiFeCoW@NC-800-13-5 & 14.52 & 0.765 & 0.541 & $6.01 \%$ \\
NiFeCoW@NC-700-10-5 & 12.96 & 0.801 & 0.565 & $5.86 \%$ \\
NiFeCoW@NC-900-10-5 & 13.72 & 0.801 & 0.551 & $6.06 \%$ \\
NiFeCoW@NC-800-10-4 & 14.37 & 0.783 & 0.525 & $5.91 \%$ \\
NiFeCoW@NC-800-10-6 & 13.78 & 0.792 & 0.530 & $5.78 \%$ \\
\hline
\end{tabular}


Table S4. Comparison of DSSC performances for NiFeCoW@NC with other typical transition metal-based catalysts.

\begin{tabular}{|c|c|c|c|c|c|}
\hline Catalyst & Electrolyte & $P C E$ & $P C E$ of $\mathrm{Pt}$ & $P C E / P C E_{\mathrm{Pt}}$ & Ref. \\
\hline NiFeCoW@NC & $\mathrm{I}_{3}^{-} / \mathrm{I}^{-}$ & $6.92 \%$ & $6.25 \%$ & 1.11 & This work \\
\hline WC(0.7)/N-HHMC & $\mathrm{I}_{3}^{-} / \mathrm{I}^{-}$ & $8.00 \%$ & $7.80 \%$ & 1.03 & {$[\mathrm{~S} 1]$} \\
\hline $\mathrm{FeNi}_{3} / \mathrm{NiFe}_{2} \mathrm{O}_{4} @ \mathrm{mGr}$ & $\mathrm{I}_{3}^{-} / \mathrm{I}^{-}$ & $12.14 \%$ & $8.31 \%$ & 1.46 & {$[\mathrm{~S} 2]$} \\
\hline Ni@NCNTs & $\mathrm{I}_{3}{ }^{-} / \mathrm{I}^{-}$ & $6.20 \%$ & $7.60 \%$ & 0.82 & {$[\mathrm{~S} 3]$} \\
\hline $\mathrm{NiMoS}_{3} / \mathrm{CNFs}$ & $\mathrm{I}_{3}{ }^{-} / \mathrm{I}^{-}$ & $8.70 \%$ & $7.53 \%$ & 1.16 & {$[\mathrm{~S} 4]$} \\
\hline $\mathrm{Fe}_{3} \mathrm{O}_{4} / \mathrm{Ni} @ \mathrm{~N}-\mathrm{RGO}$ & $\mathrm{I}_{3}^{-} / \mathrm{I}^{-}$ & $8.96 \%$ & $7.87 \%$ & 1.14 & {$[\mathrm{~S} 5]$} \\
\hline $\mathrm{NiWO}_{4} / \mathrm{BC}$ & $\mathrm{I}_{3}^{-} / \mathrm{I}^{-}$ & $7.08 \%$ & $6.46 \%$ & 1.10 & [S6] \\
\hline Ni-Co-MoS $x$ & $\mathrm{I}_{3}-/ \mathrm{I}^{-}$ & $9.63 \%$ & $8.28 \%$ & 1.16 & {$[\mathrm{~S} 7]$} \\
\hline $\mathrm{Co}-\mathrm{Cu}-\mathrm{WS}_{\mathrm{x}}$ & $\mathrm{I}_{3}^{-} / \mathrm{I}^{-}$ & $9.61 \%$ & $8.24 \%$ & 1.17 & {$[\mathrm{~S} 8]$} \\
\hline Ni-MoSex@CoSe 2 & $\mathrm{I}_{3}^{-} / \mathrm{I}^{-}$ & $9.58 \%$ & $8.32 \%$ & 1.15 & [S9] \\
\hline $\mathrm{Co}_{3} \mathrm{~S}_{4} / \mathrm{MoS}_{2}$ & $\mathrm{I}_{3}-/ \mathrm{I}^{-}$ & $8.96 \%$ & $7.77 \%$ & 1.13 & {$[\mathrm{~S} 10]$} \\
\hline
\end{tabular}


Table S5. The comparison of HER performances with the reported typical transition metal-based catalysts.

\begin{tabular}{lccc}
\hline Catalyst & $\eta_{10}(\mathrm{mV})$ & Tafel slope $\left(\mathrm{mV} \mathrm{dec}^{-1}\right)$ & Ref. \\
\hline $\mathrm{NiFeCoW} @ \mathrm{NC}$ & 127.8 & 60.4 & This work \\
\hline $\mathrm{W}-\mathrm{W}_{2} \mathrm{C} / \mathrm{CNT}$ & 155 & 56.0 & {$[\mathrm{~S} 11]$} \\
\hline $\mathrm{N}-\mathrm{NiMoS}$ & 68 & 86.0 & {$[\mathrm{~S} 12]$} \\
\hline $\mathrm{Cu} @ \mathrm{WC}$ & 92 & 50.5 & {$[\mathrm{~S} 13]$} \\
\hline $\mathrm{Ni} / \mathrm{WC} @ \mathrm{NC}$ & 53 & 43.5 & {$[\mathrm{~S} 14]$} \\
\hline $\mathrm{P}-\mathrm{NiMo}{ }_{4} \mathrm{~N}_{5} @ \mathrm{Ni}$ & 118 & 125.0 & {$[\mathrm{~S} 15]$} \\
\hline $\mathrm{W}{ }_{2} \mathrm{C} @ \mathrm{CNT}$ & 155 & 85.0 & {$[\mathrm{~S} 16]$} \\
\hline $\mathrm{WC} / \mathrm{W}_{2} \mathrm{C} @ \mathrm{C} \mathrm{NWs}$ & 69 & 52 & {$[\mathrm{~S} 17]$} \\
\hline $\mathrm{W} / \mathrm{W}_{2} \mathrm{C} @ \mathrm{NPC}$ & 55 & 43.7 & {$[\mathrm{~S} 18]$} \\
\hline $\mathrm{N}-\mathrm{WC}$ & 89 & 75.0 & {$[\mathrm{~S} 19]$} \\
\hline $\mathrm{Ni}-\mathrm{W}_{2} \mathrm{C}$ & 81 & 39.0 & {$[\mathrm{~S} 20]$} \\
\hline
\end{tabular}




\section{Supplementary References}

[S1] Srathongluan, P.; Lin, J. Y.; Chanlek, N.; Vailikhit, V.; Hasin, P. Highly efficient tungsten-doped hierarchical structural N-Enriched porous carbon counter electrode material for dye-sensitized solar cells. Electrochim. Acta. 2020, 351, 136455.

[S2] Pang, B. L.; Zhang, M. L.; Zhou, C.; Dong, H. Z.; Ma, S.; Feng, J. G.; Chen, Y. J.; Yu, L. Y.; Dong, L. F. Heterogeneous $\mathrm{FeNi}_{3} / \mathrm{NiFe}_{2} \mathrm{O}_{4}$ nanoparticles with modified graphene as electrocatalysts for high performance dye-sensitized solar cells. Chem. Eng. J. 2021, 405, 126944.

[S3] Chen, M.; Shao, L. L.; Lv, X. W.; Wang, G. C.; Yang, W. Q.; Yuan, Z. Y.; Qian, X.; Han, Y. Y.; Ding, A. X. In situ growth of Ni-encapsulated and N-doped carbon nanotubes on N-doped ordered mesoporous carbon for high-efficiency triiodide reduction in dye-sensitized solar cells. Chem. Eng. J. 2020, 390, 124633.

[S4] Li, Z. X.; Ma, Z. Y.; Zhang, X.; Du, Q. Z.; Fu, Y. H.; Shuang, L.; Yang, K.; Li, L.; Lai, W. D.; Zhang, W. M. In-situ growth $\mathrm{NiMoS}_{3}$ nanoparticles onto electrospinning synthesis carbon nanofibers as a low cost platinum-free counter electrode for dye-sensitized solar cells. J. Alloys Compd. 2021, 850, 156807.

[S5] Xu, H. F.; Jin, Z. Reasonable construction of $\mathrm{Fe}_{3} \mathrm{O}_{4} / \mathrm{Ni} @ \mathrm{~N}-\mathrm{RGO}$ nanoflowers as highly efficient counter electrodes for dye-sensitized solar cells. Sustain. Energy Fuels. 2020, 4, 3604-3612.

[S6] Zhang, Y. L.; Yun, S. N.; Wang, C.; Wang, Z. Q.; Han, F.; Si, Y. M. Bio-based carbon-enhanced tungsten-based bimetal oxides as counter electrodes for dye-sensitized solar cells. J. Power Sources. 2019, 423, 339-348. 
[S7] Qian, X.; Xu, C.; Jiang, Y. Q.; Zhang, J.; Guan, G. X.; Huang, Y. X. $\mathrm{Ni}-\mathrm{Co}-\mathrm{MoS}_{\mathrm{x}}$ ball-in-ball hollow nanospheres as Pt-free bifunctional catalysts for high-performance solar cells and hydrogen evolution reactions. Chem. Eng. J. 2019, $368,202-211$.

[S8] Qian, X.; Liu, H. Y.; Yang, J. H.; Wang, H. W.; Huang, J.; Xu, C. Co-Cu-WS ball-in-ball nanospheres as highperformance Pt-free bifunctional catalysts in efficient dye-sensitized solar cells and alkaline hydrogen evolution. J. Mater. Chem. A. 2019, 7, $6337-6347$.

[S9] Liu, H. Y.; Qian, X.; Niu, Y. D.; Chen, M.; Xu, C.; Wong, K. Y. Hierarchical $\mathrm{Ni}-\mathrm{MoSe}_{\mathrm{x}} @ \mathrm{CoSe}_{2}$ core-shell nanosphere as highly active bifunctional catalyst for efficient dye-sensitized solar cell and alkaline hydrogen evolution. Chem. Eng. J. 2020, 383, 123129.

[S10] Zhang, J.; Wu, W. M.; Zhang, C.; Ren, Z. J.; Qian, X. Prussian-blue analog-derived $\mathrm{Co}_{3} \mathrm{~S}_{4} / \mathrm{MoS}_{2}$ porous nanocubes as enhanced Pt-free electrode catalysts for high-efficiency dye-sensitized solar cells. Appl. Surf. Sci. 2019, 484, 1111-1117.

[S11] Hu,Y.; Yu, B.; Ramadoss, M.; Li, W. X.; Yang, D. X.; Wang, B.; Chen, Y. F. Scalable Synthesis of Heterogeneous W-W ${ }_{2}$ C Nanoparticle Embedded CNT Networks for Boosted Hydrogen Evolution Reaction in Both Acidic and Alkaline Media. ACS Sustainable Chem. Eng. 2019, 7, 10016-10024.

[S12] Huang, C.; Yu, L.; Zhang, W.; Xiao, Q.; Zhou, J. Q.; Zhang, Y. L.; An, P. F.; Zhang, J.; Yu, Y. N-doped Ni-Mo based sulfides for high-efficiency and stable hydrogen evolution reaction. Appl. Catal. B Environ. 2020, 276, 119137. 
[S13] Yao, M. Q.; Wang, B. J.; Sun, B. L.; Luo, L. F.; Chen, Y. J.; Wang, J. W.; Wang, N.; Komarnenib, S.; Niu, X. B.; Hu, W. C. Rational design of self-supported $\mathrm{Cu} @$ WC core-shell mesoporous nanowires for pH-universal hydrogen evolution reaction. Appl. Catal. B Environ. 2021, 280, 119451.

[S14] Ma, Y. Y.; Lang, Z. L.; Yan, L. K.; Wang, Y. H.; Tan, H. Q.; Feng, K.; Xia, Y. J.; Zhong, J.; Liu, Y.; Kang, Z. H.; Li, Y. G. High efficient hydrogen evolution triggered by a multi-interfacial Ni/WC hybrid electrocatalyst. Energy Environ. Sci. 2018, 11, 2114-2123.

[S15] Shen, F. C.; Sun, S. N.; Xin, Z. F.; Lia, S. L.; Dong, L. Z.; Huang, Q.; Wang, Y. R.; Liu, J.; Lan, Y. Q. Hierarchically phosphorus doped bimetallic nitrides arrays with unique interfaces for efficient water splitting. Appl. Catal. B Environ. 2019, 243, $470-480$.

[S16] Hussain, S.; Rabani, I.; Vikraman, D.; Feroze, A.; Karuppasamy, K.; Haq, Z.; Seo, Y. S.; Chun, S. H.; Kim, H. S.; Jung, J. W. Hybrid Design Using Carbon Nanotubes Decorated with $\mathrm{Mo}_{2} \mathrm{C}$ and $\mathrm{W}_{2} \mathrm{C}$ Nanoparticles for Supercapacitors and Hydrogen Evolution Reactions. ACS Sustainable Chem. Eng. 2020, 8, 12248-12259.

[S17] Zhang, L. N.; Ma, Y. Y.; Lang, Z. L.; Wang, Y. H.; Khan, S. U.; Yan, G.; Tan, H. Q.; Zang, H. Y.; Li, Y. G. Ultrafine cable-like $\mathrm{WC} / \mathrm{W}_{2} \mathrm{C}$ heterojunction nanowires covered by graphitic carbon towards highly efficient electrocatalytic hydrogen evolution. J. Mater. Chem. A. 2018, 6, 15395-15403.

[S18] Zhang, Q.; Luo, F.; Hu, H.; Xu, R. Z.; Qu, K. G.; Yang, Z. H.; Xu, J. X.; Cai, W. W. A robust electrocatalytic activity toward the hydrogen evolution reaction from 
$\mathrm{W} / \mathrm{W}_{2} \mathrm{C}$ heterostructured nanoparticles coated with a N,P dual-doped carbon layer. Chem. Commun. 2019, 55, 9665-9668.

[S19] Han, N.; Yang, K. R.; Lu, Z. Y.; Li, Y. J.; Xu, W. W.; Gao, T. F.; Cai, Z.; Zhang, Y.; Batista, V. S.; Liu, W.; Sun, X. M. Nitrogen-doped tungsten carbide nanoarray as an efficient bifunctional electrocatalyst for water splitting in acid. Nat. Commun. 2018, 9, 924.

[S20] Ang, E. H.; Dinh, K. N.; Sun, X. L.; Huang, Y.; Yang, J.; Dong, Z. L.; Dong, X. C.; Huang, W.; Wang, Z. G.; Zhang, H.; Yan, Q. Y. Highly Efficient and Stable Hydrogen Production in All pH Range by Two-Dimensional Structured Metal-Doped Tungsten Semicarbides. Research. 2019, 2019, 4029516. 